\title{
Meta-QTLs, Ortho-MetaQTLs and Candidate Genes for Grain yield and Associated Traits in Wheat (Triticum aestivum L.)
}

Dinesh Kumar Saini

Punjab Agricultural University

Puja Srivastava ( $\square$ pujasrivastava@pau.edu )

Punjab Agricultural University https://orcid.org/0000-0002-9260-8931

Neeraj Pal

GBPant University of Agriculture \&amp; Technology: Govind Ballabh Pant University of Agriculture \&amp; Technology

P. K. Gupta

Meerut University: Chaudhary Charan Singh University

\section{Research Article}

Keywords: wheat, grain yield, meta-QTLs, ortho-MQTLs, candidate genes, marker-assisted breeding

Posted Date: April 27th, 2021

DOI: https://doi.org/10.21203/rs.3.rs-430452/v1

License: (9) This work is licensed under a Creative Commons Attribution 4.0 International License. Read Full License 


\section{Abstract}

The present study involved meta-QTL analysis based on 8,998 QTLs, including 2,852 major QTLs for grain yield (GY) and its following ten component/related traits: (i) grain weight (GWei), (ii) grain morphology related traits (GMRTs), (iii) grain number (GN), (iv) spikes related traits (SRTs), (v) plant height (PH), (vi) tiller number (TN), (vii) harvest index (HI), (viii) biomass yield (BY), (ix) days to heading/flowering and maturity (DTH/F/M) and ( $x$ ) grain filling duration (GFD). The QTLs used for this study were retrieved from 230 reports involving 190 mapping populations (1999-2020), which also included 19 studies involving durum wheat. As many as 141 meta-QTLs were obtained with an average confidence interval of $1.37 \mathrm{cM}$ (reduced 8.87 fold), the average interval in the original QTL being $>12.15$ $\mathrm{cM}$. As many as $63 \mathrm{MQTLs}$, each based on at least 10 original QTLs were considered to be the most stable and robust with thirteen identified as breeder's meta-QTL. Meta-QTLs (MQTLs) were also utilized for identification of as many as 1,202 candidate genes (CGs), which also included 18 known genes. Based on a comparative genomics strategy, a total of 50 wheat homologues of 35 rice, barley and maize yield-related genes were also detected in these MQTL regions. Moreover, taking the advantage of synteny, a total of 24 ortho-MQTLs were detected at co-linear regions between wheat with barley, rice and maize. The present study is the most comprehensive till date, and first of its kind in providing stable and robust MQTLs and ortho-MQTLs, thus providing useful information for future basic studies and for markerassisted breeding for yield and its component traits in wheat.

\section{Introduction}

Wheat provides $~ 20 \%$ of protein and calories in human diets worldwide. Due to continuous efforts of plant breeders, the global annual production of wheat has been increasing continuously during the last five decades and reached 765 million metric tons in the year 2020. It has also been estimated that the annual production of wheat should increase by $50 \%$ by the year 2050

(https://www.openaccessgovernment.org/demand-for-wheat/83189/) to meet the demand of the growing population, which is expected to reach 9 to 10 billion in the year 2050. However, the rate of global annual wheat production declined in recent years to $0.9 \%$ from $~ 3 \%$ in the early years of the two postgreen revolutions (Shiferaw et al. 2013; Yadav et al. 2019). Therefore, further improvement in yield potential is needed to improve and sustain the required annual growth rate of $\sim 2 \%$. This will be possible only through a further detailed understanding of the genetic architecture of grain yield associated with the use of molecular approaches with conventional wheat breeding (Gupta et al. 2020).

Grain yield is widely known to be a complex quantitative trait, which is controlled by a large number of QTLs/genes involved in plant growth and development, contributing towards yield either directly or indirectly. Yield is also known to be influenced by the environment, thus making its visual selection rather difficult. Major yield contributing traits include grain number, grain weight, grain morphology-related traits, tiller number, spike-related traits, harvest index, plant height, heading date, etc. (Gupta et al. 2020; Hu et al. 2020). Therefore, these traits are continuously targeted in wheat breeding programmes for developing novel high-yielding varieties (Zhou et al. 2007). Since these yield-related traits are each controlled by a 
number of quantitative trait loci (QTLs), the markers associated with these QTLs can be exploited in molecular breeding using marker-assisted selection (MAS).

During the last two decades, a large number of QTLs for grain yield and its component traits have been identified (Table S1). However, the practical use of these QTLs seems to be minimal in actual wheat breeding. In order to make use of these QTLs in wheat breeding, and in basic research, a detailed analysis of these loci needs to be undertaken. Meta-analysis of the QTLs is an approach that has been shown to provide more robust and reliable QTLs (Goffinet and Gerber, 2000; Salvi and Tuberosa, 2015). Since, Meta-QTL analysis also allows identification of "QTL hotspots" (if any), we undertook the task of finding such regions for use by the wheat breeders.

Efforts have also been made to improve algorithms used for meta-QTL analysis (Arcade et al. 2004; de Oliveira et al. 2014; Veyrieras et al. 2007). Most of these algorithms are available in the software 'Biomercator' (Sosnowski et al. 2012). Using the maximum likelihood method, these algorithms test the number of possible meta-loci (MQTLs), which result from the projection of initial/original QTLs (taken from different studies) on a consensus genetic map. Criteria are also available to find out the best model for confirming the actual number of these MQTLs (Goffinet and Gerber, 2000; Sosnowski et al. 2012).

Wheat MQTLs have already been identified for several traits including the following: ear emergence (Hanocq et al. 2007), (ii) pre-harvest sprouting tolerance (Tyagi and Gupta, 2012), (iii) Fusarium head blight resistance (Venske et al. 2019), (iv) heat stress tolerance (Acuña-Galindo et al. 2015; Kumar et al. 2020) and (v) yield and quality-related traits (Liu et al. 2020; Quraishi et al. 2017; Soriano et al. 2017; Zhang et al. 2010). However, new QTLs are being regularly added to the database for QTLs. Most of these new QTLs have been identified using SNP arrays that have recently become available (Hu et al. 2020; Kuang et al. 2020; Lin et al. 2020; Xin et al. 2020; Yu et al. 2020). Keeping this in view, during the present study, meta-QTL analysis was conducted on grain yield (GY) and a number of its contributing traits listed above, using the QTL data from 230 studies published during 1999 to 2020 utilizing 190 different mapping populations (Table S1).

The MQTLs identified during the present study were also used to identify candidate genes (CGs). OrthoMQTLs across gramineae family were also detected using synteny among cereals (Mayer et al. 2011; Hirsch et al. 2014; Kumar et al. 2009). Genomic regions associated with MQTLs that are homologous to known genes for yield in other cereals (rice, barley, and maize) were also identified. We believe that this work should prove useful not only for genomic selection based molecular breeding, but also for basic research on structural genes and regulatory elements involved in grain yield and associated traits not only in wheat, but also in other cereals.

\section{Materials And Methods}

\section{Collection of QTL Data for Yield and Associated Traits in Wheat}


The literature related to QTL mapping of grain yield and its component traits was collected from PubMed (http://www.ncbi.nlm.nih.gov/pubmed) and Google Scholar (https://scholar.google.com/) using appropriate keywords. A total of 8,998 QTLs were available from 230 studies, which involved 190 mapping populations. The size of the mapping populations ranged from 32 to $547 \mathrm{DH} / \mathrm{RIL}$ lines; these mapping populations also included $26 \mathrm{~F}_{2}$ / $\mathrm{BC}$ populations. As many as 19 studies involved durum wheat, mainly published during 2015-2020. A summary of these QTLs studies is available in Table S1. For each QTL, the following data was retrieved: (1) QTL name, wherever available, (2) flanking markers or closely linked marker, (3) peak position and confidence interval, (4) type and size of the mapping population, (5) LOD score, and (6) phenotypic variance explained (PVE) or $\mathrm{R}^{2}$ value. Wherever, information about peak position was missing, mid-point between the two flanking markers was treated as the peak. Secondly, where LOD score was not available, the same was calculated using the available test statistic. In case, when actual LOD score for an individual QTL was not available, a threshold LOD score of 3.0 was chosen for the study.

If names of QTLs were not available, names were assigned following the standard nomenclature (letter "Q" followed by abbreviated name of the trait, the institute involved and the chromosome). Different QTLs on the same chromosome were distinguished by using numerical identifiers following the chromosome. All QTLs were accommodated in the following traits: (i) 'grain weight' (GWei), recorded as thousand-grain weight, 50-grains weight, mean grain weight, hundred-grain weight, single grain weight, grain weight per plant, and test weight, (ii) 'grain number' (GN) recorded as average grain number per spike, grain number per spike, grain number per square meter, grain number per spikelet, grains per spikelet, and grains per fertile spikelet, etc; (iii) 'grain morphology related traits' (GMRTs) recorded as grain length, grain width, grain length-width ratio, grain thickness, grain thickness-length ratio, grain area, and grain diameter, grain volume weight, etc.; (iv) 'spike related traits' (SRTs) recorded as spike length, spikes per plant, spikes per square meter, spike compactness, spike formation rate, spike layer uniformity, basal sterile spikelet number, top sterile spikelet number, fertile floret per spike, and spikelets per spike, etc. (v) 'biomass yield' (BY) recorded as total biomass, tiller biomass, and plant biomass; (vi) 'tiller number' (TN) recorded as effective tiller number, tiller number per plant, and tiller number per square meter. Other remaining traits were treated individually by the available name of the trait (e.g., heading, days to flowering, days to maturity, grain filling duration, earliness per se, and plant height).

\section{Construction of Consensus Map}

A consensus map (described as Wheat_Consensus_2021) was developed using the following integrated genetic maps: (1) the 'Wheat_Composite_2004' map with 4403 marker loci, available at GrainGenes database (http://wheat.pw.usda.gov); (2) the 'Wheat, Consensus SSR, 2004' with 1235 marker loci (Somer et al. 2004); (3) an integrated map for durum wheat with 3669 markers (Marone et al. 2013); (4) four SNP maps developed using different SNP arrays as follows: 'Illumina 9K iSelect Beadchip Array' (Cavanagh et al. 2013) and 'Illumina iSelect 90K SNP Array' (Wang et al. 2014), 'Wheat 55K SNP array' (Winfield et al. 2016), the 'AxiomR, Wheat 660K SNP array' (Cui et al. 2017). Marker information or maps from several 
other independent studies were also included for developing the consensus map. The R package LPMerge was employed for the construction of the consensus map (Endelman and Plomion, 2014).

\section{QTL Projection and Meta-QTL analysis}

Only 7,275 QTLs from 8,998 available QTLs had the information required for QTL projection. Although, from these 7,275 QTLs, only 2,852 major QTLs (explaining $\geq 10$ percent of phenotypic variance for the target trait), each with the required information (estimated Cls, peak positions, original LOD scores, and $\mathrm{R}^{2}$ or PVE value) could be used for projection on the consensus map using BioMercator V4.2 (Sosnowski et al. 2012) (Table S1).

To ensure consistency in different studies, the confidence interval (95\%) was estimated for each locus, through different population-specific equations: for RILs: $\mathrm{Cl}=163$ / (population size $\times \mathrm{R}^{2}$ ); for $\mathrm{F}_{2}$ and backcross populations: $\mathrm{Cl}=530 /\left(\right.$ population size $\times \mathrm{R}^{2}$ ); and for $\mathrm{DH}: \mathrm{Cl}=287 /\left(\right.$ population size $\times \mathrm{R}^{2}$ ) (Darvasi and Soller, 1997; Venske et al. 2019). Following projection, meta-analysis was performed, for each chromosome individually, via the Veyrieras two-step algorithm available in the software. The Akaike (AIC) statistics were used to find the best QTL model for ascertaining the actual number of MQTLs on each wheat chromosome. The statistical procedures and algorithms furnished in this software have been well-described elsewhere (Sosnowski et al. 2012).

\section{Candidate Gene mining within MQTLs and Expression Analysis}

For identification of CGs, the sequences for flanking markers of individual MQTLs were retrieved from GrainGenes (https://wheat.pw.usda.gov/GG3) and CerealsDB (https://www.cerealsdb.uk.net/cerealgenomics/CerealsDB/indexNEW.php) and used for BLASTN searches against wheat reference genome sequence available in the EnsemblPlants (http://plants.ensembl.org/index.html). Physical positions of the GBS-SNPs were directly obtained from URGI database (https://wheat-urgi.versailles.inra.fr/). Among the MQTLs obtained, those with a $\mathrm{Cl}$ of $\leq$ $2 \mathrm{Mb}$ were directly used for identification of the candidate genes (CGs). In the remaining cases with longer $\mathrm{Cl}$, a $2 \mathrm{Mb}$ genomic region (including $1 \mathrm{MB}$ region on either side of the MQTL peak) was examined for possible candidate genes. Gene models present within the original or estimated physical regions were retrieved using 'BioMart' of EnsemblPlant database. The function annotations of the identified gene models were explored to find the best candidate genes within each MQTL.

For the in-silico transcriptional analysis, the identified putative candidate genes (CGs) were analyzed via the 'Wheat Expression Browser-expVIP' (expression Visualization and Integration Platform) (http://www.wheat-expression.com) (Ramírez-González et al. 2018). Gene expression datasets relevant to the present study were utilized for this purpose, including 'Developmental time-course of chinese spring (Choulet et al. 2014) and synthetic hexaploid' (Li et al. 2014); 'Grain tissue specific developmental timecourse' (Gillies et al. 2012; Pearce et al. 2015; Pfeifer et al. 2014); 'Chinese spring leaves and roots at both seedling (Clavijo et al. 2017) and seven leaf stages' (Ramírez-González et al. 2018), and 'Gene expression during a time-course of flag leaf senescence' (Borrill et al. 2019). Following the criteria proposed by 
Wagner and co-workers (2013), only CGs showing at least 2 transcripts per million (TPM) expression were considered in this study. Heat maps for expression data were constructed using the same online resource 'expVIP'.

CGs were further examined using information from cloned, and characterized wheat genes for the traits of interest. Nucleotide sequences of these collected genes were obtained from the NCBI database (https://www.ncbi.nlm.nih.gov/) using accession IDs given in the respective published studies and then BLASTN searches were carried out against the genomic database (available in EnsemblPlants) of wheat to find the physical positions of these genes in the genome.

\section{MQTL Regions homologous to known genes in other cereals}

Information on rice, barley, and maize genes associated with grain yield and related traits was collected from the literature and used for retrieval of the corresponding protein sequences for the identification of homologous MQTL genomic regions. Amino acid sequences for relevant genes were retrieved from the NCBI (https://www.ncbi.nlm.nih.gov/) and used for BLASTP search to identify the wheat protein (available in EnsemblPlants) at an E-value of $<10-10$, with $60 \%$ coverage, and $>60 \%$ identity. Physical positions of the corresponding genes and wheat MQTLs were then compared to detect the MQTL regions homologous to known genes in other cereals.

\section{Results}

\section{QTLs Associated with Grain Yield and Related Traits in Wheat}

The trait-wise distribution of total QTLs, along with QTLs having information required for meta QTL analysis and major QTLs associated with different yield traits is presented in Table 1. The distribution of these QTLs on different wheat sub-genomes is shown in Fig. 1. Among the three sub-genomes, the subgenome A carried 3,457 (38.42\%) QTLs, sub-genome B carried 3,566 (39.63\%) QTLs and the sub-genome D carried only $1,975(21.94 \%)$ QTLs.

\section{Construction Of The Consensus Map}

The integrated consensus map contained 2,33,856 markers, which included a variety of markers including the following types: SNPS, DArT, SSR, AFLP, RAPD, STS, EST-SSR, SRAP, ISSR and KASP markers. Following important genes are also included on this consensus maps: Vrn, Ppd, Rht, and Glu loci (Table S2). The total length of the consensus map is $11,638.76 \mathrm{cM}$; the length of individual chromosome ranged from $281.26 \mathrm{cM}(4 \mathrm{D})$ to $763.08 \mathrm{cM}(4 \mathrm{~A})$. The average number of markers carried by a single chromosome was 11,136 (Table S3). The marker densities for individual linkage groups ranged from 12.76 to 48.27 markers per $\mathrm{CM}$ for $\mathrm{A}$ and $\mathrm{B}$ sub-genomes, and 7.74 to 18.13 markers for $\mathrm{D}$ sub-genome.

\section{Ortho-mqtls In Barley, Rice And Maize}

The next question, that is natural outcome of MQTL study is what will be the status of other crops, will they be harbouring similar MQTLs in their genomic regions. The study was further advanced to search 
such orthologues in Gramineae family. For identification of ortho-MQTLs, 27 stable and robust wheat MQTLs were selected, each, based on > 20 QTLs. As many as 24 corresponding MQTLs (so called orthoMQTLs) of these wheat MQTLs were identified in rice, barley and maize genomes; ortho-MQTLs for three wheat MQTLs (MQTL1A.5, MQTL2A.2, and MQTL3A.4) were not identified on any syntenic chromosome of the studied species; the details are as follows: (i) five ortho-MQTLs mainly associated with traits GY, GWei, and PH in wheat and maize, (ii) ortho-MQTLs of 11 wheat MQTLs in syntenic regions of rice and maize, and (iii) two ortho-MQTLs (ortho-MQTL2D.5 and ortho-MQTL5A.3) in syntenic regions of maize and barley. Among these, 6 ortho-MQTLs (ortho-MQTL2B.3, ortho-MQTL4A.3; ortho-MQTL4B.1; orthoMQTL4B.5, ortho-MQTL7A.3, and ortho-MQTL7B.1) involved MQTLs in all the four crops (Table 3).

Conclusively, ortho-MQTLs were detected on five barley chromosomes $2 \mathrm{H}, 4 \mathrm{H}, 5 \mathrm{H}$, and $7 \mathrm{H}$; each of which comprised only one previously detected MQTLs. In rice, ortho-MQTLs were identified on all the chromosomes except chromosomes 1, 9, and 10, and underlying MQTLs ranged from 1 (on chromosome 2) to 8 (on chromosome 4) MQTLs. In maize, ortho-MQTLs were detected on all the ten chromosomes, number of MQTLs within the ortho-MQTL regions ranged from 1 to 16 MQTLs. The remaining information about ortho-MQTLs identified between wheat with barley, rice, and maize are given in Table 3 and the traits associated with these ortho-MQTLs and underlying orthologous genes along with their functional descriptions are presented in Table S5.

\section{Candidate Genes For Wheat Mqtls}

Gene mining in genomic regions carrying individual MQTL allowed the identification of 2,953 gene models; this number was reduced to 2,298, when following classes were removed: (i) duplicated genes from overlapping MQTLs; (ii) genes with no information available regarding molecular function and gene ontology (GO) terms. The in-silico expression analysis of the above gene models (except the gene models underlying three MQTLs) allowed the identification of 1,202 gene models, each showing at least 2 transcripts per million (TPM) expression (highlighted with yellow in Table S6). The gene models showed spatio-temporal gene expression, expressing in different plant tissues such as grains, spikes, leaves, shoots, and roots, etc. at specific times during development (for instance, see Fig. 3). Detailed information regarding these gene models, hereafter, termed as 'putative CGs' detected in different MQTL regions is provided in Table S6. These 1,202 CGs mainly belonged to the five major gene classes, including, (i) transcription factors, (ii) genes involved in metabolism and/or signalling of growth regulators- gibberellins, cytokinins and brassinosteroids, (iii) genes regulating cell division and proliferation (iv) floral regulators, and (v) genes involved in regulation of carbohydrate metabolism (Table S7).

Several known yield related genes were also mapped within the MQTLs regions (Table S8); 18 such genes were available, which included the following: TaSnRK2.3-1B (MQTL1B.7), TaCwi-A1 (MQTL2A.2), TaCYP78A5-2D (MQTL2D.8), FRIZZY PANICLE (MQTL2D.5), Btr1-A (MQTL3A.3), TaPSTOL and TaSnRK2.9-5A (MQTL5A.3), DEP1-5A (MQTL5A.4), TaCWI5D (MQTL5D.4), DEP1-5D (MQTL5D.5), 
TaSPL21-6A, TaGW2-6A, TaPRR1-6A, and TaBT1-6A (MQTL6A.2), TaBT1-6B, TaPRR1-6B, and TaSPL216B (MQTL6B.10), and TaGS3 (MQTL7A.1).

\section{Wheat MQTLs with Homology to Known Genes from Other Cereals}

Known genes for yield and its components from other cereals including rice, barley, and maize were also used for the identification of putative wheat CGs in MQTL regions; this allowed identification of 24 putative wheat CGs of the 48 available rice genes, 3 of the 7 available barley genes and 8 of the available 13 maize genes. Of these 24 rice genes, as many as 12 genes (viz., D2, DEP1, An-1, GW2, GIF1, qGL3, $S M G 1$, OsLG3, OSALMT7, GS9, OSPK2, and FZP) showed more than one homologues, while, remaining twelve genes showed only one homologue each in wheat MQTL regions (Table 4 and S10). No wheat homologues in MQTL regions were available for four barley genes (Ert-m, HVAPETALA2, HVLUX1, and INTC), while, two barley genes (vrs4 and COM1) each gave more than one wheat homologues and one gene showed a single homologue (Table 4 and S10). For 8 maize genes (FASCIATED EAR2, ramosa2, ZmFrk1, bs1, BIF1, ZmGS3, KNR6 and vt2), 12 wheat homologues were available in different MQTL regions. In some cases, more than one homologues were available within the same MQTL regions, for instance, homologues of rice genes $A n-1, G I F 4, G W 2$, and OSPK2 were detected in the MQTL2A.2 region, homologues of rice genes $D 11$, GIF1, OsPK2, and FZP rice genes were available in MQTL2D.8 region and homologues of Vrs4 (barley), ramosa2, vt2 (maize) were available in MQTL3A.3 region (Table 4).

Overall, 33 MQTL regions contained 50 wheat homologues involving 35 alien yield genes from other three cereals (rice, barley, and maize). To our knowledge, homologues of only 8 of these 34 alien genes (GW2, GIF1, GS3, DEP1, CKX2, OSSPL 14, FZP, and ZmVT2) have already been cloned and characterized in wheat; following are the details of these wheat homologues: TaGW2 (Su et al. 2011), TaCwi-A1 (Ma et al. 2012), TaGS-D1 (Zhang et al. 2014), DEP1 (Vavilova et al. 2017), TaCKX family genes (Ogonowska et al. 2019), TaSPL 14 (Cao et al. 2021), FRIZZY PANICLE (FZP) (Dobrovolskaya et al. 2015), and TaTAR2.1 (Shao et al. 2017).

\section{Discussion}

During the past two decades, starting with the first QTL studies on yield-related traits published by Araki et al. (1999) and Kato et al. (1999), a large number of of studies have been conducted on QTL mapping for grain yield and its component traits in wheat (Table S1). The studies involving development of MQTLs were largely motivated by the fact that only a small fraction of QTLs identified by interval mapping are major QTLs, and majority of QTLs are each associated with a large confidence interval, with flanking markers often located away from the QTLs, thus making these QTLs not very useful for plant breeding. Also, QTLs identified using one bi-parental population may not be effective for a breeding programme involving other parents, without prior validation, unless the markers are functional markers located within the QTLs. These problems can be largely overcome through development of MQTLs, which are robust with a reduced confidence interval, thus increasing the utility of these MQTLs not only in crop 
improvement programmes, but also for basic studies involving cloning and characterizing QTLs/genes for the trait of interest.

Meta-QTL analysis has been conducted for a variety of traits in all major crops. In wheat, meta-QTL analysis has been conducted for a number of traits including yield, but the information on MQTLs soon becomes out-of-date. This is largely because, a large number of studies on QTL analysis for yield traits in wheat are regularly conducted, thus creating a need for conducting further studies on MQTLs periodically to obtain improved MQTLs. The present study is one such attempt, conducted to improve upon MQTLs reported so far for grain yield and associated traits in wheat (Bilgrami et al. 2020; Gegas et al. 2010; Griffiths et al. 2009; Griffiths et al. 2012; Liu et al. 2020; Quraishi et al. 2017; Zhang et al. 2010). The maximum number of QTLs used for these earlier meta-QTL studies on yield traits in wheat was 381 for hexaploid wheat (including the QTLs detected under heat and drought stress conditions) and 1,162 (including the QTLs for disease resistance, grain yellow pigment content, grain quality traits, and root architecture-related traits) for durum wheat leading to identification of a maximum of 55 MQTLs for hexaploid wheats (Liu et al. 2020; Zhang et al. 2010) and 71 for durum wheats (Maccaferri et al. 2019). In contrast to this, the number of available QTLs that we listed were 8,998, of which 2,852 major QTLs were used for identification of as many as $141 \mathrm{MQTLs} \mathrm{suggesting} \mathrm{that} \mathrm{the} \mathrm{present} \mathrm{study} \mathrm{is} \mathrm{so} \mathrm{far} \mathrm{the} \mathrm{most}$ comprehensive study for identification of MQTLs in wheat.

With the availability of improved algorithms, software, and recently available resources such as high quality genomic and transcriptomic data (Appels et al. 2018; Borrill et al. 2019; Choulet et al. 2014; Clavijo et al. 2017; Pearce et al. 2015; Ramírez-González et al. 2018) the study was more demanding but effective in identification of better MQTLs. Hopefully, some of the MQTLs identified during the present study will be relatively more robust, since the number of initial QTLs per MQTL could be as high as 71 (MQTL5A.2). As many as 24 MQTLs identified during the present study had their genetic positions almost overlapping those occupied by MQTLs reported in two recent studies (Bilgrami et al. 2020; Liu et al. 2020), so that these MQTLs can be used in future studies with a higher level of confidence (Table S4). On a critical evaluation of these 24 MQTLs, we selected 15 MQTLs each involving atleast 10 initial QTLs, which should be tried in molecular breeding and future studies for cloning and characterization of QTLs/genes (Table S4).

\section{Breeder's Mqtls}

Following the criteria laid down by Löffler et al. (2009), from a total of 141 MQTLs identified during the present study, we selected thirteen most promising MQTLs, and described these MQTLs as "Breeder's MQTLs", each of which had a $\mathrm{Cl}$ of $<2 \mathrm{cM}$. Also, these MQTLs explained a significant proportion of phenotypic variance (ranging from 20.73 to $49.16 \%$ ) associated with high LOD values (ranging from 14.05 to 62.67 ) (Table 2). For example, one MQTL having high PVE (49.16\%) can be called a mega breeder MQTL located on 3D.1 for traits GWei, GMRTs and PH. Therefore, these MQTLs have the potential to serve as most efficient targets for their direct use in MAS for wheat improvement or can be treated as major genes. Another important feature of the present study is the availability of clusters of MQTLs, 
which included one cluster each on seven different chromosomes (Fig. 2). These clusters of MQTLs may be treated as hotspots and should be utilized for breeding and for future basic research with high level of confidence.

\section{Ortho-mqtls For Cereals}

For the present analysis, we took a step ahead for identification of Ortho-MQTLs, since these are conserved and may be recommended for use in all cereals. Conserved nature of these orthoMQTLs also suggest that these may represent some regulatory genes (Jin et al. 2015; Khahani et al. 2020; Quraishi et al. 2011). Keeping this in view, we selected a total of twenty-seven most promising wheat MQTLs to investigate their evolutionary conserved syntenic regions (or so called ortho-MQTLs) reported in similar meta-QTL analysis studies on the yield-related traits in maize, barley, and rice (Table 3). Consequently, 24 ortho-MQTLs were identified for yield and associated traits conserved at orthologous positions in the barley, rice and maize. As many as six of these 24 ortho-MQTLs identified in the present study were crossspecies in all the four crops, revealing the high level of conservation of wheat with barley, maize and rice. Of the CGs underlying these ortho-MQTLs, precise orthologous gene sets can be considered as direct potential candidates for further homology-based cloning, functional validation or at least as a source of accurate molecular markers such as conserved orthologous set (COS) markers for use in cereal breeding programs.

Among earlier studies on ortho-MQTLs in wheat, conducted using the above cross-genome map based strategy, an ortho-MQTL associated with nitrogen use efficiency was earlier discovered. This ortho-MQTL was common for all cereals including wheat, maize, sorghum, and rice, which enabled characterization of a structurally and functionally important conserved gene 'glutamate synthase' (GoGAT) at orthologous positions in a number of species (Quraishi et al. 2011). In another study, ortho-MQTLs associated with grain iron and zinc were identified using rice MQTL. Further dissection of these ortho-MQTL regions led to the identification of two maize genes of rice, namely GRMZM2G178190, and GRMZM2G366919. These genes were characterized as natural resistance-associated macrophage protein genes and considered to be the best candidate genes associated with grain iron and zinc in maize (Jin et al. 2015). The orthoMQTLs identified during the present study can also be subjected to similar studies leading to identification of orthologs.

\section{Candidate Genes For Mqtls}

The QTLome for grain yield and its component traits is also believed to have a significant correlation with gene density in the wheat genome (Maccaferri et al. 2019). In the present study, gene mining was performed in all MQTL regions (in $\leq$ the $2 \mathrm{Mb}$ region) and a total of 2298 gene models were identified. Of these, 703 gene models/putative CGs produced 2 to 5 TPM expressions (highlighted with yellow in Table S6), whereas, as many as 489 gene models showed more than 5 TPM expression (highlighted with blue in Table S6) in different plant tissues at different times (spatio-temporal gene expression). As mentioned earlier, these putative CGs mainly belonged to five major categories of the genes which are known to be 
involved in controlling the grain yield and associated traits in cereals (Daba et al. 2020; Nadolska-Orczyk et al. 2017) (Table S7).

MQTLs with genes/gene families involved in grain yield and its component traits has also been shown in several studies (Daba et al. 2020; Gautam et al. 2019; Gunupuru et al. 2018; Jia et al. 2020; Li and Wei, 2020; Ma et al. 2017; Nadolska-Orczyk et al. 2017; Niño-González et al. 2019; Sakuma et al. 2018). In the present study, several such genes/gene families with similar functions were detected repeatedly in different MQTL regions, including 114 genes for leucine-rich repeat proteins, 63 genes for serine/threonine-protein kinases, 33 genes for cytochrome $\mathrm{P} 450$ proteins and 14 genes each for WD40/YVTN repeat-like containing proteins, UDP-glucuronosyl/UDP-glucosyltransferases, FAD/NAD(P) binding proteins, and E3 ubiquitin ligases, etc (Table S6). Moreover, some genes encoding unpredicted or uncharacterized proteins also showed significant expression in different plant tissues (Table S6). These genes deserve further attention, to explore their possible roles in the regulation of yield and its component traits in wheat.

For many MQTL regions, it was also possible to identify several F-box-like domain superfamily, UDPglucuronosyl/UDP-glucosyltransferase, etc. (Table S6). These gene clusters are quite common in plant genomes and are known to encode proteins involved in many enzymatic pathways in plants (Medema et al. 2015; Yi et al. 2007). It has also been shown in these studies that members of a gene cluster can be located in close proximity (only a few thousand base pairs far from each other) in a small genomic region, and also encoding similar products/proteins, thus together sharing a generalized function.

We selected as many as 162 promising putative CGs which had more than 5 TPM expression in different tissues (Table 5). An extensive survey of available literature also shows association of these selected genes with the traits of interest in different plant species. These CGs may be cloned and further characterized and then can be exploited through biotechnological approaches such as transgenesis and gene editing. In a more recent study, it was observed that over-expression of the expansin gene in developing seeds minimizes the trade-off between grain number and grain weight, and ultimately improves the grain yield. Transgenic plants with enhanced expression of the Expansin gene yielded 12.3 $\%$ higher grain weight compared to the control, which finally translated into an $11.3 \%$ increase in grain yield under field conditions (Calderini et al. 2020). In the present study, we also identified many putative CGs, including genes for Expansin proteins in some MQTL regions (Table 5, Table S6). In future, the targeted transgenic approach using these potential CGs may allow improvement for grain yield in wheat. However, in some cases, where gene clusters regulate the expression of target trait, the transgenic method using a single gene may not be as effective as MAS, where flanking markers can target a much larger region encompassing all the genes of a cluster.

MQTL regions were also examined for genes already known to be associated with yield and its component traits; as many as 18 such wheat genes were identified. These genes encode a variety of proteins including the following: cell wall invertase, sucrose non-fermenting 1-related protein kinase, squamosa promoter binding protein-like protein, E3 ubiquitin ligase, APETALA2/AP2/ERF transcription 
factor, cytochrome P450 protein, phosphatidylethanolamine binding protein, and transmembrane protein, etc. Similar proteins/products are also encoded by many other CGs, identified in the present study. Therefore, these CGs can be used for further functional analysis. Some of the MQTLs also had flanking markers associated with known genes including $\mathrm{Vrn}, \mathrm{Ppd}$, and Rht genes, that are widely known to regulate plant phenology, ultimately influencing the grain yield and other component traits in wheat (Gupta et al. 2020; Kamran et al. 2014).

\section{Wheat homologues of rice, barley and maize genes}

During the present study, within the wheat MQTL regions, we also identified several wheat homologues of genes that are known to control grain yield and related traits in rice, barley, and maize genes; many of these genes have not yet been cloned and functionally characterized in wheat; these genes include the following: (i) rice genes: An-1, Bsg1, D11, D2, LP, PGL 1, qGL3, SMG1, OsOTUB1, OsLG3, OsDHHC1, OsY37, qWS8, OsALMT7, GS9, GSN1, OsPS1-F, and OsPK2; (ii) barley genes: vrs4 and COM1 and (iii) maize genes: FASCIATED EAR2, ramosa2, ZmFrk1, bs1, KNR6, and BIF1 (Table 4, Table S9). Using comparative genomics, orthologs of these genes can be characterized in wheat and their functional markers can be developed and validated. For instance, in a study conducted in 2018, a meta-analysis of QTLs associated with grain weight in tetraploid wheat resulted in the identification of one important locus, mQTL-GW-6A on chromosome 6A. Further analysis identified and characterized a wheat homolog of the rice gene, OsGRF4 within this MQTL region (Avni et al. 2018). This suggests that integrating an MQTL study with a well-annotated genome can rapidly lead to the detection of CGs underlying traits of interest.

This was an in-silico approach for improvement of our understanding of the genetic architecture of grain yield and its component traits in wheat through identification of MQTLs, orthoMQTLs, and candidate genes. The study involved an integration of the available information about QTLs that were identified in earlier studies along with genomic and transcriptomic resources of the wheat. As many as $141 \mathrm{MQTLs}$, each associated with a narrow confidence interval and 1,202 putative CGs were identified. Thirteen of these 141 MQTLs regions given as breeder's QTL, we recommend for use in MAS for grain yield improvement in wheat. Based on a comparative genomic approach, several wheat homologs of rice, barley, and maize yield-related genes were also detected in the MQTL regions. The ortho-MQTL analysis demonstrated that MQTLs of yield-related traits appear to be transferable to other cereal crops that that may assist breeding programs in cereals. As many as 162 of 1,202 putative CGs are also recommended for future basic studies including cloning and functional characterization. However, after any in-silico analysis of this type, the in-vivo confirmation and/or validation of any of these loci, specifically the CGs identified, is needed, which can be accomplished via further approaches, such as gene cloning, reverse genetic approaches, gene silencing followed by transcriptomics, proteomics, and metabolomics. We hope that the results of the present study will help in developing a better insight into the genetic architecture and molecular mechanisms underlying grain yield and its component traits in wheat and other cereals. The information on the molecular markers linked with the MQTLs and CGs occupying the MQTL region may also prove useful in breeding for grain yield improvement in wheat. 


\section{Key Message:}

The study used 8998 QTLs reported in earlier studies in wheat and identified 141 MQTLs, 162 putative CGs and thirteen breeder's QTL, for grain yield improvement.

\section{Declarations}

\section{Acknowledgments}

Thanks are due to the Department of Science and Technology (DST), New Delhi, India for providing INSPIRE fellowship to DKS and to Head, Department of Plant Breeding and Genetics, Punjab Agricultural University, Ludhiana, (India) for providing necessary facilities.

\section{Authors' contribution}

D.K.S., P.S. and P.K.G. conceived and designed the project; P.K.G. and P.S. supervised the study; D.K.S. and N.P. conducted the analysis; D.K.S. wrote the paper and P.K.G. and P.S. corrected the final draft. All authors read and approved the final manuscript.

\section{Funding}

This research received no external funding.

\section{Compliance with ethical standards}

Conflict of interest: The authors declare that they have no competing interests.

\section{Availability of data and material}

Data generated or analysed during this study are included in this published article (and its Supplementary material 1). Datasets are also available from the corresponding author on reasonable request.

\section{References}

Acuña Galindo MA, Mason RE, Subramanian NK Hays DB (2015) Meta analysis of wheat QTL regions associated with adaptation to drought and heat stress. Crop Sci 55:477-492

Appels R, Eversole K, Stein N, Feuillet C, Keller B, Rogers J, Pozniak CJ, Choulet F, Distelfeld A, Poland J, Ronen $G$ (2018) Shifting the limits in wheat research and breeding using a fully annotated reference genome. Science 361:6403

Araki E, Miura H, Sawada S (1999) Identification of genetic loci affecting amylose content and agronomic traits on chromosome 4A of wheat. Theor Appl Genet 98:977-984 
Arcade A, Labourdette A, Falque M, Mangin B, Chardon F, Charcosset A, Joets J (2004)

BioMercator:integrating genetic maps and QTL towards discovery of candidate

genes. Bioinformatics 20:2324-2326

Bommert P, Nagasawa NS, Jackson D (2013) Quantitative variation in maize kernel row number is controlled by the FASCIATED EAR2 locus. Nat Genet 45:334-337

Borrill P, Harrington SA, Simmonds J, Uauy C (2019) Identification of transcription factors regulating senescence in wheat through gene regulatory network modeling. Plant Physiol 180:1740-1755

Bortiri E, Chuck G, Vollbrecht E, Rocheford T, Martienssen R, Hake S (2006) ramosa2 encodes a LATERAL ORGAN BOUNDARY domain protein that determines the fate of stem cells in branch meristems of maize. The Plant Cell 18:574-585

Sheng Z, Wu Y, Shao G, Xie L, Peng C, Xu J, Tang S, Wei X

Calderini DF, Castillo FM, Arenas MA, Molero G, Reynolds MP, Craze M, Bowden S, Milner MJ, Wallington EJ, Dowle A, Gomez LD (2020) Overcoming the trade-off between grain weight and number in wheat by the ectopic expression of expansin in developing seeds leads to increased yield potential. New Phytol 230:629-640.

Cavanagh CR, Chao S, Wang S, Huang BE, Stephen S, Kiani S, Forrest K, Saintenac C, Brown-Guedira GL, Akhunova A, See D (2013) Genome-wide comparative diversity uncovers multiple targets of selection for improvement in hexaploid wheat landraces and cultivars. Proc Natl Acad Sci 110:8057-8062

Chuck G, Muszynski M, Kellogg E, Hake S, Schmidt RJ (2002) The control of spikelet meristem identity by the branched silkless1 gene in maize. Science 298:1238-1241

Cui F, Zhang N, Fan XL, Zhang W, Zhao CH, Yang LJ, Pan RQ, Chen M, Han J, Zhao XQ, Ji J (2017) Utilization of a Wheat660K SNP array-derived high-density genetic map for high-resolution mapping of a major QTL for kernel number. Sci Rep 7:1-12

Daba SD, Liu X, Aryal U, Mohammadi M (2020) A proteomic analysis of grain yield-related traits in wheat. AoB Plants 12:plaa042

Darvasi A, Soller M (1997) A simple method to calculate resolving power and confidence interval of QTL map location. Behav Genet 27:125-132

de Oliveira Y, Sosnowski O, Charcosset A, Joets J (2014) BioMercator 4:A complete framework to integrate QTL, meta-QTL, and genome annotation. European Conference on Computational Biology 2014, Sep 2014, Strasbourg, France

Dobrovolskaya O, Pont C, Sibout R, Martinek P, Badaeva E, Murat F, Chosson A, Watanabe N, Prat E, Gautier N, Gautier V (2015) FRIZZY PANICLE drives supernumerary spikelets in bread wheat. Plant 
Duan P, Rao Y, Zeng D, Yang Y, Xu R, Zhang B, Dong G, Qian Q, Li Y (2014) Small grain1 which encodes a mitogen-activated protein kinase kinase 4 influences grain size in rice. The Plant J 77:547-557

El Mannai Y, Akabane K, Hiratsu K, Satoh-Nagasawa N, Wabiko H (2017) The NAC transcription factor gene OsY37 (ONAC011) promotes leaf senescence and accelerates heading time in rice. Int J Mol Sci 18:2165

Endelman JB, Plomion C (2014) LPmerge:an R package for merging genetic maps by linear programming. Bioinformatics 30:1623-1624

Galli M, Liu Q, Moss BL, Malcomber S, Li W, Gaines C, Federici S, Roshkovan J, Meeley R, Nemhauser JL, Gallavotti A (2015) Auxin signaling modules regulate maize inflorescence architecture. Proc Natl Acad Sci $112: 13372-13377$

Galuszka P, Frébortová J, Werner T, Yamada M, Strnad M, Schmülling T, Frébort I (2004) Cytokinin oxidase/dehydrogenase genes in barley and wheat: cloning and heterologous expression. Eur J Biochem 271:3990-4002

Gautam T, Saripalli G, Gahlaut V, Kumar A, Sharma PK, Balyan HS, Gupta PK (2019) Further studies on sugar transporter (SWEET) genes in wheat (Triticum aestivum L). Mol Biol Rep 46:2327-2353

Gegas VC, Nazari A, Griffiths S, Simmonds J, Fish L, Orford S, Sayers L, Doonan JH, Snape JW (2010) A genetic framework for grain size and shape variation in wheat. The Plant Cell 22:1046-1056

Gillies SA, Futardo A, Henry RJ (2012) Gene exprssion in the developing aleurone and starchy endosperm of wheat. Plant Biotechnol J 10:668-679

Goffinet B, Gerber S (2000) Quantitative trait loci: a meta-analysis. Genetics 155:463-473

Griffiths S, Simmonds J, Leverington M, Wang Y, Fish L, Sayers L, Alibert L, Orford S, Wingen L, Herry L, Faure S (2009) Meta-QTL analysis of the genetic control of ear emergence in elite European winter wheat germplasm. Theor Appl Genet 119:383-395

Gunupuru LR, Arunachalam C, Malla KB, Kahla A, Perochon A, Jia J, Thapa G, Doohan FM (2018) A wheat cytochrome P450 enhances both resistance to deoxynivalenol and grain yield. PloS One 13:e0204992

Guo T, Chen K, Dong NQ, Shi CL, Ye WW, Gao JP, Shan JX, Lin HX (2018) GRAIN SIZE AND NUMBER1 negatively regulates the OsMKKK10-0sMKK4-OsMPK6 cascade to coordinate the trade-off between grain number per panicle and grain size in rice. The Plant Cell 30:871-888

Gupta PK, Balyan HS, Sharma S, Kumar R (2020) Genetics of yield, abiotic stress tolerance and biofortification in wheat (Triticum aestivum L). Theor Appl Genet 133:1569-1602 
Hanocq E, Laperche A, Jaminon O, Lainé AL, Le Gouis J (2007) Most significant genome regions involved in the control of earliness traits in bread wheat, as revealed by QTL meta-analysis. Theor Appl Genet 114:569-584

Heang D, Sassa H (2012) An atypical bHLH protein encoded by POSITIVE REGULATOR OF GRAIN LENGTH 2 is involved in controlling grain length and weight of rice through interaction with a typical bHLH protein APG. Breed Sci 62:133-141

Heng Y, Wu C, Long Y, Luo S, Ma J, Chen J, Liu J, Zhang H, Ren Y, Wang M, Tan J (2018) OsALMT7 maintains panicle size and grain yield in rice by mediating malate transport. The Plant Cell 30:889-906

Hirsch CN, Foerster JM, Johnson JM, Sekhon RS, Muttoni G, Vaillancourt B, Peñagaricano F, Lindquist E, Pedraza MA, Barry K, de Leon N (2014) Insights into the maize pan-genome and pan-transcriptome. The Plant Cell 26:121-135

Hong Z, Ueguchitanaka M, Umemura K, Uozu S, Fujioka S, Takatsuto S, Yoshida S, Ashikari M, Kitano H, Matsuoka M (2003) A rice brassinosteroid-deficient mutant ebisu dwarf (d2) is caused by a loss of function of a new member of cytochrome P450. The Plant Cell 15:2900-2910

Hu J, Wang X, Zhang G, Jiang P, Chen W, Hao Y, Ma X, Xu S, Jia J, Kong L, Wang H (2020) QTL mapping for yield-related traits in wheat based on four RIL populations. Theor Appl Genet 133:917-933

Jia H, Li M, Li W, Liu L, Jian Y, Yang Z, Shen X, Ning Q, Du Y, Zhao R, Jackson D (2020) A serine/threonine protein kinase encoding gene KERNEL NUMBER PER ROW6 regulates maize grain yield. Nat Commun $11: 1-11$

Jin T, Chen J, Zhu L, Zhao Y, Guo J, Huang Y (2015) Comparative mapping combined with homologybased cloning of the rice genome reveals candidate genes for grain zinc and iron concentration in maize. BMC Genet 16:1-15

Kamran A, Iqbal M, Spaner D (2014) Flowering time in wheat (Triticum aestivum L):a key factor for global adaptability. Euphytica 197:1-26

Kato K, Miura H, Sawada S (1999) QTL mapping of genes controlling ear emergence time and plant height on chromosome 5A of wheat. Theor Appl Genet 98:472-477

Koppolu R, Anwar N, Sakuma S, Tagiri A, Lundqvist U, Pourkheirandish M, Rutten T, Seiler C, Himmelbach A, Ariyadasa R, Youssef HM (2013) Six-rowed spike4 (Vrs4) controls spikelet determinacy and row-type in barley. Proc Natl Acad Sci 110:13198-13203

Kuang CH, Zhao XF, Yang K, Zhang ZP, Ding L, Pu ZE, Ma J, Jiang QT, Chen GY, Wang JR, Wei YM (2020) Mapping and characterization of major QTL for spike traits in common wheat. Physiol Mol Biol Plants 26:1295-130 
Kumar A, Saripalli G, Jan I, Kumar K, Sharma PK, Balyan HS, Gupta PK (2020) Meta-QTL analysis and identification of candidate genes for drought tolerance in bread wheat (Triticum aestivum $\mathrm{L}$ ). Physiol Mol Biol Plants 26:1713-1725

Li Q, Yang X, Bai G, Warburton ML, Mahuku G, Gore M, Dai J, Li J, Yan J (2010) Cloning and characterization of a putative GS3 ortholog involved in maize kernel development. Theor Appl Genet 120:753-763

Li Y, Wei K (2020) Comparative functional genomics analysis of cytochrome P450 gene superfamily in wheat and maize. BMC Plant Biol 20:1-22

Lin Y, Jiang X, Tao Y, Yang X, Wang Z, Wu F, Liu S, Li C, Deng M, Ma J, Chen G (2020) Identification and validation of stable quantitative trait loci for grain filling rate in common wheat (Triticum aestivum L). Theor Appl Genet 133:2377-2385

Liu E, Liu Y, Wu G, Zeng S, Tran Thi TG, Liang L, Liang Y, Dong Z, She D, Wang H, Zaid IU (2016) Identification of a candidate gene for panicle length in rice (Oryza sativa $\mathrm{L}$ ) via association and linkage analysis. Front Plant Sci 7:596

Liu H, Mullan D, Zhang C, Zhao S, Li X, Zhang A, Lu Z, Wang Y, Yan G (2020) Major genomic regions responsible for wheat yield and its components as revealed by meta-QTL and genotype-phenotype association analyses. Planta 252:1-22

Löffler M, Schön CC, Miedaner T (2009) Revealing the genetic architecture of FHB resistance in hexaploid wheat (Triticum aestivum L) by QTL meta-analysis. Mol Breed 23:473-488

Luo J, Liu H, Zhou T, Gu B, Huang X, Shangguan Y, Zhu J, Li Y, Zhao Y, Wang Y, Zhao Q (2013) An-1 encodes a basic helix-loop-helix protein that regulates awn development grain size and grain number in rice. Plant Cell 25:3360.

Ma D, Yan J, He Z, Wu L, Xia X (2012) Characterization of a cell wall invertase gene TaCwi-A1 on common wheat chromosome 2A and development of functional markers. Mol Breed 29:43-52

Ma L, Zhang D, Miao Q, Yang J, Xuan Y, Hu Y (2017) Essential role of sugar transporter OsSWEET11 during the early stage of rice grain filling. Plant Cell Physiol 58:863-873

Mao H, Sun S, Yao J, Wang C, Yu S, Xu C, Li X, Zhang Q (2010) Linking differential domain functions of the GS3 protein to natural variation of grain size in rice. Proc Natl Acad Sci 107:19579-84

Marone D, Russo MA, Laidò G, De Vita P, Papa R, Blanco A, Gadaleta A, Rubiales D, Mastrangelo AM (2013) Genetic basis of qualitative and quantitative resistance to powdery mildew in wheat:from consensus regions to candidate genes. BMC Genom 14:562 
Mayer KF, Martis M, Hedley PE, Šimková H, Liu H, Morris JA, Steuernagel B, Taudien S, Roessner S, Gundlach H, Kubaláková M (2011) Unlocking the barley genome by chromosomal and comparative genomics. The Plant Cell 23:1249-1263

Medema MH, Kottmann R, Yilmaz P, Cummings M, Biggins JB, Blin K, De Bruijn I, Chooi YH, Claesen J, Coates RC, Cruz-Morales P (2015) Minimum information about a biosynthetic gene cluster. Nat Chem Biol $11: 625-631$

Miura K, Ikeda M, Matsubara A, Song XJ, Ito M, Asano K, Matsuoka M, Kitano H, Ashikari M (2010) OsSPL14 promotes panicle branching and higher grain productivity in rice. Nat Genet 42:545-549

Nadolska-Orczyk A, Rajchel IK, Orczyk W, Gasparis S (2017) Major genes determining yield-related traits in wheat and barley. Theor Appl Genet 130:1081-1098

Niño-González M, Novo-Uzal E, Richardson DN, Barros PM, Duque P (2019) More transporters more substrates:The Arabidopsis major facilitator superfamily revisited. Mol Plant 12:1182-1202

Pfeifer M, Kugler KG, Sandve SR, Zhan B, Rudi H, Hvidsten TR, Mayer KF, Olsen OA, International Wheat Genome Sequencing Consortium (2014) Genome interplay in the grain transcriptome of hexaploid bread wheat. Science 345:6194

Phillips KA, Skirpan AL, Liu X, Christensen A, Slewinski TL, Hudson C, Barazesh S, Cohen JD, Malcomber S, McSteen $P$ (2011) vanishing tassel2 encodes a grass-specific tryptophan aminotransferase required for vegetative and reproductive development in maize. The Plant Cell 23:550-566

Poursarebani N, Trautewig C, Melzer M, Nussbaumer T, Lundqvist U, Rutten T, Schmutzer T, Brandt R, Himmelbach A, Altschmied L, Koppolu R (2020) COMPOSITUM 1 contributes to the architectural simplification of barley inflorescence via meristem identity signals. Nat Commun 11:1-16

Qi P, Lin YS, Song XJ, Shen JB, Huang W, Shan JX, Zhu MZ, Jiang L, Gao JP, Lin HX (2012) The novel quantitative trait locus GL31 controls rice grain size and yield by regulating Cyclin-T1; 3 . Cell Res 22:16661680

Quraishi UM, Pont C, Ain QU, Flores R, Burlot L, Alaux M, Quesneville H, Salse J (2017) Combined genomic and genetic data integration of major agronomical traits in bread wheat (Triticum aestivum $\mathrm{L}$ ). Front Plant Sci 8:1843

Ramamoorthy R, Vishal B, Ramachandran S, Kumar PP (2018) The OsPS1-F gene regulates growth and development in rice by modulating photosynthetic electron transport rate. Plant Cell Rep 37:377-385

Ren D, Hu J, Xu Q, Cui Y, Zhang Y, Zhou T, Rao Y, Xue D, Zeng D, Zhang G, Gao Z (2018) FZP determines grain size and sterile lemma fate in rice. J Exp Bot 69:4853-4866 
Sakuma S, Golan G, Guo Z, Ogawa T, Tagiri A, Sugimoto K, Bernhardt N, Brassac J, Mascher M, Hensel G, Ohnishi S (2018) Unleashing floret fertility by a mutated homeobox gene improved grain yield during wheat evolution under domestication. Biorxiv p434985

Salvi S, Tuberosa R (2015) The crop QTLome comes of age. Curr. Opin. Biotechnol. 32:179-185

Shao A, Ma W, Zhao X, Hu M, He X, Teng W, Li H, Tong Y (2017) The auxin biosynthetic TRYPTOPHAN AMINOTRANSFERASE RELATED TaTAR2 1-3A increases grain yield of wheat. Plant Physiol 174:22742288

Shiferaw B, Smale M, Braun HJ, Duveiller E, Reynolds M, Muricho G (2013) Crops that feed the world 10 Past successes and future challenges to the role played by wheat in global food security. Food Security 5:291-317

Somers DJ, Isaac P, Edwards K (2004) A high-density microsatellite consensus map for bread wheat (Triticum aestivum L). Theor Appl Genet 109:1105-1114

Song X J Huang W Shi M, Zhu MZ, Lin HX (2007) A QTL for rice grain width and weight encodes a previously unknown ring-type E3 ubiquitin ligase. Nat Genet 39:623

Soriano JM, Malosetti M, Roselló M, Sorrells ME Royo C (2017) Dissecting the old Mediterranean durum wheat genetic architecture for phenology, biomass and yield formation by association mapping and QTL meta-analysis. PLoS One 12:e0178290

Sosnowski O, Charcosset A, Joets J (2012) BioMercator V3:an upgrade of genetic map compilation and quantitative trait loci meta-analysis algorithms. Bioinformatics 28:2082-2083

Sun H, Qian Q, Wu K, Luo J, Wang S, Zhang C, Ma Y, Liu Q, Huang X, Yuan Q, Han R (2014) Heterotrimeric $G$ proteins regulate nitrogen-use efficiency in rice. Nat Genet $46: 652$

Tanabe S Ashikari M Fujioka S, Takatsuto S, Yoshida S, Yano M, Yoshimura A, Kitano H, Matsuoka M, Fujisawa Y, Kato H (2005) A novel cytochrome P450 is implicated in brassinosteroid biosynthesis via the characterization of a rice dwarf mutant dwarf11 with reduced seed length. Plant Cell 17:776

Tyagi S, Gupta PK (2012) Meta-analysis of QTLs involved in pre-harvest sprouting tolerance and dormancy in bread wheat. Triticeae Genomics and Genetics 3:9-24

Vavilova V, Konopatskaia I, Kuznetsova AE, Blinov A, Goncharov NP (2017) DEP1 gene in wheat species with normal compactoid and compact spikes. BMC Genet 18:106

Venske E, Dos Santos RS, Farias DDR, Rother V, da Maia LC, Pegoraro C, Costa de Oliveira A (2019) Metaanalysis of the QTLome of Fusarium head blight resistance in bread wheat:refining the current puzzle. Front Plant Sci 10:727 
Veyrieras JB, Goffinet B, Charcosset A (2007) MetaQTL:a package of new computational methods for the meta-analysis of QTL mapping experiments. BMC Bioinformatics 8:49

Wang E, Wang J, Zhu X, Hao W, Wang L, Li Q, Zhang L, He W, Lu B, Lin H, Ma H (2008) Control of rice grain-filling and yield by a gene with a potential signature of domestication. Nat Genet 40:1370

Wang S, Wong D, Forrest K, Allen A, Chao S, Huang BE, Maccaferri M, Salvi S, Milner SG, Cattivelli L, Mastrangelo AM (2014) Characterization of polyploid wheat genomic diversity using a high density 90 000 single nucleotide polymorphism array. Plant Biotechnol J 12:787-796

Wang S, Wu K, Qian Q, Liu Q, Li Q, Pan Y, Ye Y, Liu X, Wang J, Zhang J, Li S (2017) Non-canonical regulation of SPL transcription factors by a human OTUB1-like deubiquitinase defines a new plant type rice associated with higher grain yield. Cell Res 27:1142-1156

Winfield MO, Allen AM, Burridge AJ, Barker GL, Benbow HR, Wilkinson PA, Coghill J, Waterfall C, Davassi A, Scopes G, Pirani A (2016) High density SNP genotyping array for hexaploid wheat and its secondary and tertiary gene pool. Plant Biotechnol J 14:1195-1206

Xin F, Zhu T, Wei S, Han Y, Zhao Y, Zhang D, Ma L, Ding Q (2020) QTL Mapping of Kernel Traits and Validation of a Major QTL for Kernel Length-Width Ratio Using SNP and Bulked Segregant Analysis in Wheat. Sci Rep10:1-12

Yadav OP, Singh DV, Dhillon BS, Mohapatra T (2019) India's evergreen revolution in cereals. 116:18051808

Yan D, Zhou Y, Ye S, Zeng L, Zhang X, He Z (2013) BEAK-SHAPED GRAIN 1/TRIANGULAR HULL 1 a DUF640 gene is associated with grain shape size and weight in rice. Sci China Life Sci 56:275-283

Yi G, Sze S-H, Thon MR (2007) Identifying clusters of functionally related genes in genomes. Bioinformatics 23:1053-1060

Yu J, Xiong H, Zhu X, Zhang H, Li H, Miao J, Wang W, Tang Z, Zhang Z, Yao G, Zhang Q (2017) OsLG3 contributing to rice grain length and yield was mined by Ho-LAMap. BMC Biol 15:28

Yu M, Liu ZH, Yang B, Chen H, Zhang H, Hou DB (2020) The contribution of photosynthesis traits and plant height components to plant height in wheat at the individual quantitative trait locus level. Sci Rep 10:1-10

Zhang L, Yu H, Ma B, Liu G, Wang J, Wang J, Gao R, Li J, Liu J, Xu J, Zhang Y (2017) A natural tandem array alleviates epigenetic repression of IPA1 and leads to superior yielding rice. Nat Commun 8:1-10 
Zhang LY, Liu DC, Guo XL, Yang WL, Sun JZ, Wang DW Zhang A (2010) Genomic distribution of quantitative trait loci for yield and yield related traits in common wheat. J Integr Plant Biol 52:996-1007

Zhang S, Nichols SE, Dong JG (2003) Cloning and characterization of two fructokinases from maize. Plant Sci 165:1051-1058

Zhang Y, Liu J, Xia X, He Z (2014) TaGS-D1 an ortholog of rice OsGS3 is associated with grain weight and grain length in common wheat. Mol Breed 34:1097-1107

Zhao DS, Li QF, Zhang CQ, Zhang C, Yang QQ, Pan LX, Ren XY, Lu J, Gu MH, Liu QQ (2018) GS9 acts as a transcriptional activator to regulate rice grain shape and appearance quality. Nat Commun 9:1-14

Zhou B, Lin JZ, Peng D, Yang YZ, Guo M, Tang DY, Tan X, Liu XM (2017) Plant architecture and grain yield are regulated by the novel DHHC-type zinc finger protein genes in rice (Oryza sativa L). Plant Sci 254:1221

Zhou Y, He ZH, Sui XX, Xia XC, Zhang XK, Zhang GS (2007) Genetic improvement of grain yield and associated traits in the northern China winter wheat region from 1960 to 2000. Crop Sci 47:245-253

\section{Tables}

Table 1 The trait wise distribution of total QTLs, along with QTLs having information required for analysis and major QTLs associated with studied traits

\begin{tabular}{|c|c|c|c|c|c|c|c|c|c|c|c|c|c|}
\hline & \multirow[t]{2}{*}{ Trait categories } & \multicolumn{4}{|c|}{ Total reported QTLs } & \multicolumn{4}{|c|}{$\begin{array}{l}\text { QTLs with information required } \\
\text { for analysis }\end{array}$} & \multicolumn{4}{|c|}{$\begin{array}{c}\text { Major QTLs } \\
\text { (selected for analysis) }\end{array}$} \\
\hline & & \multicolumn{4}{|c|}{ Sub-genomes } & \multicolumn{4}{|c|}{ Sub-genomes } & \multicolumn{4}{|c|}{ Sub-genomes } \\
\hline $\begin{array}{l}\text { Sr. } \\
\text { no. }\end{array}$ & & A & B & D & Total & A & B & D & Total & A & B & D & Total \\
\hline 1. & GY & 176 & 230 & 111 & 517 & 137 & 186 & 89 & 412 & 68 & 83 & 54 & 205 \\
\hline 2. & GWei & 592 & 622 & 337 & 1551 & 474 & 497 & 273 & 1244 & 191 & 203 & 93 & 487 \\
\hline 3. & GN & 361 & 312 & 128 & 801 & 314 & 264 & 108 & 686 & 132 & 115 & 37 & 284 \\
\hline 4. & GMRTs & 604 & 680 & 386 & 1670 & 484 & 557 & 314 & 1355 & 184 & 196 & 107 & 487 \\
\hline 5. & SRTs & 1055 & 963 & 598 & 2616 & 843 & 792 & 462 & 2097 & 306 & 259 & 189 & 754 \\
\hline 6. & BY and HI & 71 & 86 & 36 & 193 & 63 & 80 & 30 & 173 & 26 & 48 & 19 & 93 \\
\hline 7. & $\begin{array}{l}\text { DTH/F/M, GFD, } \\
\text { EPS }\end{array}$ & 288 & 371 & 196 & 855 & 215 & 274 & 133 & 622 & 84 & 108 & 72 & 264 \\
\hline 8. & $\begin{array}{l}\mathrm{PH} \\
\end{array}$ & 259 & 272 & 157 & 688 & 235 & 226 & 134 & 595 & 69 & 90 & 69 & 228 \\
\hline 9. & TN & 51 & 30 & 26 & 107 & 44 & 24 & 23 & 91 & 25 & 12 & 13 & 50 \\
\hline & Total & 3,457 & 3,566 & 1,975 & 8,998 & 2,809 & 2,900 & 1,566 & 7,275 & 1,085 & 1,114 & 653 & 2,852 \\
\hline
\end{tabular}

Table 2 Yield-related MQTLs identified in the present study 


\begin{tabular}{|c|c|c|c|c|}
\hline $\begin{array}{l}\text { Sr. } \\
\text { no. }\end{array}$ & $\begin{array}{c}\text { MQTL name (CI, } \\
\text { in } \mathrm{cM})\end{array}$ & Flanking markers & $\begin{array}{c}\text { bInitial } \\
\text { QTLs (avg. } \\
\text { LOD } \\
\text { score) }\end{array}$ & Traits (avg. PVE) \\
\hline 1. & $\begin{array}{l}\text { MQTL1A.1 } \\
(21.58-22.51)\end{array}$ & AX-110506772/AX-109884241 & $4(8.41)$ & GWei, GY, and SRTs (12.37) \\
\hline 2. & $\begin{array}{l}\text { MQTL1A.2 } \\
(30.39-31.33)\end{array}$ & IWB45602/AX-111475421 & $10(6.76)$ & SRTs, GMRTs, and TW (14.54) \\
\hline 3. & $\begin{array}{l}\text { MQTL1A.3 } \\
(39.14-40.2)\end{array}$ & AX-109896396/AX-95156759 & $11(7.03)$ & $\begin{array}{l}\text { GMRTs, GN, SRTs, GWei, and GY } \\
(22.75)\end{array}$ \\
\hline 4. & $\begin{array}{l}\text { MQTL1A.4 } \\
(45.62-46.48)\end{array}$ & AX-109272204/AX-94547512 & $2(9.15)$ & SRTs (21.30) \\
\hline 5. & $\begin{array}{l}\text { MQTL1A.5 } \\
(48.7-49)\end{array}$ & AX-110597220/AX-111596418 & $23(6.53)$ & $\begin{array}{l}\text { SRTs, PH, GWei, GN, TN, GMRTs, } \\
\text { DTF, and HI (17.92) }\end{array}$ \\
\hline 6. & $\begin{array}{l}\text { MQTL1A.6 } \\
(49.31-50.2)\end{array}$ & IWB64888/Xcfe26.5 & $2(9.17)$ & GN (22.73) \\
\hline 7. & $\begin{array}{l}\text { MQTL1A.7 } \\
(51.91-52.5)\end{array}$ & AX-95129506/AX-94383313 & $2(4.54)$ & SRTs and GMRTs (11.85) \\
\hline 8. & $\begin{array}{l}\text { MQTL1A.8 } \\
(58.82-58.95)\end{array}$ & IWA4240/AX-94492795 & $23(5.47)$ & $\begin{array}{l}\text { GMRTs, GN, BY, SRTs, GY, GWei, } \\
\text { and TN (16.27) }\end{array}$ \\
\hline 9. & $\begin{array}{l}\text { MQTL1B.1 } \\
(11.97-12.18)\end{array}$ & IWB54702.1/IWB28576 & $8(8.25)$ & SRTs and DTF (18.74) \\
\hline 10. & $\begin{array}{l}\text { MQTL1B.2 } \\
(48.18-50.07)\end{array}$ & AX-94888336/AX-95186655 & $4(8.70)$ & GMRTs and GWei (16.69) \\
\hline 11. & $\begin{array}{l}\text { MQTL1B.3 } \\
(77.2877 .9)\end{array}$ & IWB57219/AX-95223114 & $7(7.52)$ & SRTs, and GMRTs (16.20) \\
\hline 12. & $\begin{array}{l}\text { aMQTL1B.4 } \\
(88.96-89.64)\end{array}$ & IWB43001/IWB12258 & $6(38.62)$ & $\begin{array}{l}\text { TN, SRTs, GWei, and GMRTs } \\
(26.60)\end{array}$ \\
\hline 13. & $\begin{array}{l}\text { MQTL1B.5 } \\
(93.01-93.2)\end{array}$ & IWB61919/IWB11925.1 & $45(5.10)$ & $\begin{array}{l}\text { GMRTs, SRTs, DTM, DTF, HI, } \\
\text { GWei, GY, GN, TN, BY, GFD, and } \\
\text { PH (14.52) }\end{array}$ \\
\hline 14. & $\begin{array}{l}\text { MQTL1B.6 } \\
(95.73-96.06)\end{array}$ & IWB47571/IWB8902 & $25(7.12)$ & $\begin{array}{l}\text { GN, DTH, SRTs, BY, GMRTs, } \\
\text { DTF, and GWei (15.57) }\end{array}$ \\
\hline 15. & $\begin{array}{l}\text { MQTL1B.7 } \\
(103.4-104.59)\end{array}$ & IWB8913/Ku_c20478_390 & $19(5.86)$ & $\begin{array}{l}\text { GWei, DTF, HI, SRTs, GMRTs, } \\
\text { EPS, GY, GN (17.29) }\end{array}$ \\
\hline 16. & $\begin{array}{l}\text { MQTL1B.8 } \\
(114.34-114.52)\end{array}$ & IWB35083/Xutv1391b & $14(4.51)$ & $\begin{array}{l}\text { GWei, SRTs, GMRTs, EPS, DTM, } \\
\text { TN, GY and PH (12.72) }\end{array}$ \\
\hline 17. & $\begin{array}{l}\text { MQTL1D.1 } \\
(15.75-25.05)\end{array}$ & AX-95104817/XGli1 & $3(6.78)$ & SRTs, TN, and DTF (16.18) \\
\hline 18. & $\begin{array}{l}\text { MQTL1D.2 } \\
\text { (70.42-70.93) }\end{array}$ & IWA6621/IWB35174 & $6(7.34)$ & GMRTs, SRTs, and GWei (12.74) \\
\hline 19. & $\begin{array}{l}\text { MQTL1D.3 } \\
(76.32-83.79)\end{array}$ & IWB60500.2/AX-94653386 & $3(6.61)$ & GY, GWei, and PH (14.82) \\
\hline 20. & $\begin{array}{l}\text { MQTL1D.4 } \\
(95.78-96.28)\end{array}$ & P32/M59-2/1DS_1914495_3816 & $7(5.06)$ & DTH, DTM, GWei and GN (15.00) \\
\hline 21. & $\begin{array}{l}\text { MQTL1D.5 } \\
(106.49-113.89)\end{array}$ & XksuE18a/AX-94555171 & $3(5.34)$ & SRTs, GWei, and PH (14.06) \\
\hline 22. & $\begin{array}{l}\text { MQTL1D.6 } \\
(118.51-122.11)\end{array}$ & Xwmc63.1/IWB23920 & $3(3.52)$ & GMRT and GWei (14.18) \\
\hline 23. & $\begin{array}{l}\text { MQTL2A.1 } \\
(122.34-123.24)\end{array}$ & BS00021739_51/GENE-1031_48 & $19(9.95)$ & $\begin{array}{l}\text { SRTs, GMRTs GN, PH, GY, DTM, } \\
\text { DTH, and GWei (17.77) }\end{array}$ \\
\hline 24. & $\begin{array}{l}\text { MQTL2A.2 } \\
(142.74-143.76)\end{array}$ & IAAV1587/IWB14868 & $26(10.67)$ & $\begin{array}{l}\text { GMRTs GN, GWei, SRTs, HI, BY, } \\
\text { PH, and DTH (15.19) }\end{array}$ \\
\hline 25. & $\begin{array}{l}\text { MQTL2A.3 } \\
(151.07-153.05)\end{array}$ & AX-95140204/AX-109425280 & $12(5.58)$ & $\begin{array}{l}\text { SRTs, GWei, GN, and GMRTs } \\
(14.70)\end{array}$ \\
\hline 26. & $\begin{array}{l}\text { MQTL2A.4 } \\
(158.76-159.04)\end{array}$ & Xwmc630b/AX-108741878 & $4(9.26)$ & SRTs, GN, and GWei (13.04) \\
\hline 27. & ${ }^{\mathrm{a} M Q T L 2 A .5}$ & AX-110428539/IWB43373 & $4(39.33)$ & GWei, and GMRTs (34.67) \\
\hline
\end{tabular}




\begin{tabular}{|c|c|c|c|c|}
\hline & (162.13-162.23) & & & \\
\hline 28. & $\begin{array}{l}\text { MQTL2A.6 } \\
(162.64-163.12)\end{array}$ & IWB43373/tPt-9405 & $20(6.38)$ & $\begin{array}{l}\text { GY, GN, DTH, DTM, SRTs, } \\
\text { GMRTs and GWei (20.41) }\end{array}$ \\
\hline 29. & $\begin{array}{l}\text { MQTL2A.7 } \\
(187.13-187.29)\end{array}$ & Ppd-A1/Xgpw2204 & $7(4.18)$ & $\begin{array}{l}\text { SRTs, GWei, TN, and GMRTs } \\
\text { (13.38) }\end{array}$ \\
\hline 30. & $\begin{array}{l}\text { MQTL2B.1 } \\
(72.48-73.36)\end{array}$ & IWB40903/IWB17530 & $10(7.29)$ & $\begin{array}{l}\text { SRTs, GN, GMRTs GY, and GWei } \\
(12.66)\end{array}$ \\
\hline 31. & $\begin{array}{l}\text { MQTL2B.2 } \\
(83.24-84.5)\end{array}$ & IWB65267.1/IWB41081 & $6(6.63)$ & SRTs, GMRTs and GWei (14.44) \\
\hline 32. & $\begin{array}{l}\text { MQTL2B.3 } \\
(102.57-103.78)\end{array}$ & IWB65370.2/IWB45990 & $31(7.07)$ & $\begin{array}{l}\text { SRTs, DTM, GN, GMRTs, GY, HI, } \\
\text { GWei, DTH, DTF, and PH (15.92) }\end{array}$ \\
\hline 33. & $\begin{array}{l}\text { MQTL2B.4 } \\
(114.43-114.98)\end{array}$ & IWB35771/IWB30649 & $16(10.55)$ & $\begin{array}{l}\text { HI, DTH, GN, GMRTs, SRTs, PH, } \\
\text { and DTF }(16.21)\end{array}$ \\
\hline 34. & $\begin{array}{l}\text { MQTL2B.5 } \\
(118.09-118.26)\end{array}$ & IWB64873/IWB28040 & $31(7.05)$ & $\begin{array}{l}\text { GMRTs, GWei, GN, GY, BY, SRTs, } \\
\text { PH, DTH, and HI (17.29) }\end{array}$ \\
\hline 35. & $\begin{array}{l}\text { MQTL2B.6 } \\
(126.62-127.31)\end{array}$ & IWB26439/wPt-0746 & $35(9.50)$ & $\begin{array}{l}\text { SRTs, GMRTs, DTF, GY, DTH, } \\
\text { DTM, GN, GWei, HI, TN, and PH } \\
(17.64)\end{array}$ \\
\hline 36. & $\begin{array}{l}\text { MQTL2B.7 } \\
(170.03-170.04)\end{array}$ & AX-94911223/Xwmc617.1 & $7(7.02)$ & $\begin{array}{l}\text { GN, PH, GY, SRTs, and GWei } \\
(15.37)\end{array}$ \\
\hline 37. & $\begin{array}{l}\text { MQTL2D.1 (0.1- } \\
0.65)\end{array}$ & Xbarc114/AX-94611751 & $9(8.70)$ & $\begin{array}{l}\text { GY, SRTs, HI, DTH, DTM, and } \\
\text { DTF (19.75) }\end{array}$ \\
\hline 38. & $\begin{array}{l}\text { MQTL2D.2 (6.8- } \\
7.36)\end{array}$ & 3033925|F|0/3029203|F|0 & $16(8.40)$ & $\begin{array}{l}\text { GWei, GMRTs, GY, PH, SRTs, and } \\
\text { DTH (17.59) }\end{array}$ \\
\hline 39. & $\begin{array}{l}\text { MQTL2D.3 } \\
(35.55-48.99)\end{array}$ & PPD-D1/AX-110595669 & $3(41.13)$ & DTH and SRTs (32.13) \\
\hline 40. & $\begin{array}{l}\text { MQTL2D.4 } \\
(59.46-61.31)\end{array}$ & AX-110668803/2DS_5365757_8955 & $9(6.22)$ & $\begin{array}{l}\text { SRTs, GWei, GY, GMRTs, PH, HI, } \\
\text { and GN (14.92) }\end{array}$ \\
\hline 41. & $\begin{array}{l}\text { MQTL2D.5 } \\
(67.72-68.15)\end{array}$ & AX-94750495/wPt-0330 & $35(7.62)$ & $\begin{array}{l}\text { GWei, GN, GY, GMRTs, SRTs, HI, } \\
\text { PH, DTH, and DTM (15.93) }\end{array}$ \\
\hline 42. & $\begin{array}{l}\text { MQTL2D.6 } \\
(76.43-76.84)\end{array}$ & 2DS_5390826_7647/Estssr-143 & $38(8.96)$ & $\begin{array}{l}\text { GMRTs, DTM, DTH, GWei, SRTs, } \\
\text { PH, BY, GY, and GN (18.07) }\end{array}$ \\
\hline 43. & $\begin{array}{l}\text { MQTL2D.7 } \\
(89.87-90.61)\end{array}$ & Xfba400/AX-94743556 & $36(9.07)$ & $\begin{array}{l}\text { SRTs, GWei, GMRTs PH, DTH, } \\
\text { GY, and DTM (19.11) }\end{array}$ \\
\hline 44. & $\begin{array}{l}\text { MQTL2D.8 } \\
(100.1-100.15)\end{array}$ & AX-110939188/JD_c63957_1176 & $11(11.31)$ & $\begin{array}{l}\text { GMRTs, TN, GN, GWei, GY, PH, } \\
\text { and SRTs (14.73) }\end{array}$ \\
\hline 45. & $\begin{array}{l}\text { MQTL3A.1 } \\
(40.14-40.52)\end{array}$ & IWB73673/Xgpw7080 & $11(6.09)$ & $\begin{array}{l}\text { SRTs, PH, GMRTs, GWei, DTM, } \\
\text { and GN (12.96) }\end{array}$ \\
\hline 46. & $\begin{array}{l}\text { MQTL3A.2 } \\
(45.02-45.38)\end{array}$ & IWB13817/3960111 & $12(4.65)$ & GN, GY, PH, and GWei (16.24) \\
\hline 47. & $\begin{array}{l}\text { MQTL3A.3 } \\
(52.56-54.93) \\
\end{array}$ & XPacgMctg13/Xwmc532 & $7(4.37)$ & $\begin{array}{l}\text { GN, SRTs, DTH, PH, and GMRTs } \\
(15.26)\end{array}$ \\
\hline 48. & $\begin{array}{l}\text { MQTL3A.4 } \\
(68.17-68.73)\end{array}$ & AX-111488679/Xbcd372 & $21(5.53)$ & $\begin{array}{l}\text { SRTs, GWei, GMRTs, PH, GY, GN, } \\
\text { HI, DTM and DTH (17.73) }\end{array}$ \\
\hline 49. & $\begin{array}{l}\text { MQTL3A.5 } \\
(71.86-72.41)\end{array}$ & wPt-440/wPt-731120 & $29(5.38)$ & $\begin{array}{l}\text { DTH, GY, GMRTs, PH, DTF, SRTs, } \\
\text { GWei, GN, and HI }(17.88)\end{array}$ \\
\hline 50. & $\begin{array}{l}\text { MQTL3A.6 } \\
(78.1-79.66)\end{array}$ & Xfba167.1/P41/M41-4 & $18(4.92)$ & $\begin{array}{l}\text { GMRTs, HI, PH, SRTs, GY, GN, } \\
\text { DTH, and GWei (16.98) }\end{array}$ \\
\hline 51. & $\begin{array}{l}\text { MQTL3A.7 } \\
(89.7-90.45)\end{array}$ & AX-110954980/Xmwg22 & $24(5.83)$ & $\begin{array}{l}\text { GWei, SRTs, GN, DTM, GY, DTH, } \\
\text { and GMRTs (17.87) }\end{array}$ \\
\hline 52. & $\begin{array}{l}\text { MQTL3A.8 } \\
(115.44-115.65)\end{array}$ & D-4261525/IWB34397 & $8(7.61)$ & GN, SRTs, and PH (16.16) \\
\hline 53. & $\begin{array}{l}\text { MQTL3B.1 } \\
(82.91-83.3)\end{array}$ & IWB65330/IWB23552 & $11(6.69)$ & $\begin{array}{l}\text { GWei, GMRTs, GN, SRTs, and PH } \\
(11.71)\end{array}$ \\
\hline 54. & $\begin{array}{l}\text { MQTL3B.2 } \\
(90.02-91.06)\end{array}$ & AX-95189982/AX-94802037 & $3(5.96)$ & SRTs, HI, and GWei (12.01) \\
\hline 55. & $\begin{array}{l}\text { MQTL3B.3 } \\
(96.31-98.38)\end{array}$ & XPaccMcga6/IWB5714 & $42(5.81)$ & $\begin{array}{l}\text { GN, GMRTs, SRTs, GY, BY, PH, } \\
\text { GN, GWei, DTF, DTH, and TN } \\
(17.10)\end{array}$ \\
\hline
\end{tabular}




\begin{tabular}{|c|c|c|c|c|}
\hline 56. & \begin{tabular}{|l} 
MQTL3B.4 \\
$(105.69-106.47)$ \\
\end{tabular} & |S-1090569/D-3946304 & $14(7.47)$ & $\begin{array}{l}\text { PH, GN, GWei, SRTs, GMRTs, BY, } \\
\text { DTF, and GY (15.74) }\end{array}$ \\
\hline 57. & $\begin{array}{l}\text { MQTL3B.5 } \\
(115.05-115.25)\end{array}$ & D-3941476/D-3532755 & $8(5.44)$ & $\begin{array}{l}\text { BY, GMRTs, GY, GN, and GWei } \\
(15.79)\end{array}$ \\
\hline 58. & $\begin{array}{l}\text { MQTL3B.6 } \\
(119.94-123.07)\end{array}$ & D-4329780/AX-94925740 & $4(5.91)$ & GY, SRTs, and GMRTs (12.99) \\
\hline 59. & $\begin{array}{l}\text { MQTL3B.7 } \\
(148.23-148.57)\end{array}$ & D-1370637/D-1216223 & $6(6.76)$ & $\begin{array}{l}\text { GWei, GY, TN, DTH, and SRTs } \\
(14.07)\end{array}$ \\
\hline 60. & $\begin{array}{l}{ }^{\mathrm{a} M Q T L 3 D} .1 \\
(1.29-2.23)\end{array}$ & IWB17932/wPt-1336 & $5(62.67)$ & GWei, GMRTs and PH (49.16) \\
\hline 61. & $\begin{array}{l}\text { MQTL3D.2 } \\
(17.05-22.9)\end{array}$ & AX-109300980/Xwmc11 & $4(4.02)$ & GWei, DTH, and GN (13.94) \\
\hline 62. & $\begin{array}{l}\text { MQTL3D.3 } \\
(35.65-37.62) \\
\end{array}$ & Xcfd4.1/Xgwm1243 & $2(4.11)$ & SRTs and GN (12.71) \\
\hline 63. & $\begin{array}{l}\text { MQTL3D.4 } \\
(50.89-51.79)\end{array}$ & AX-110430652/AX-109688927 & $2(5.17)$ & SRTs and TN (14.55) \\
\hline 64. & $\begin{array}{l}\text { MQTL3D.5 } \\
(54.43-54.72)\end{array}$ & AX-110430652/AX-109688927 & $5(4.82)$ & GWei, GN, and SRTs (23.01) \\
\hline 65. & $\begin{array}{l}\text { MQTL3D.6 } \\
(58.69-59.45)\end{array}$ & AX-111337684/Xwmc529 & $2(7.04)$ & PH and SRTs (11.62) \\
\hline 66. & $\begin{array}{l}\text { MQTL3D.7 } \\
(68.35-69.39)\end{array}$ & TaCKX6a02-D1/CKX3D/AX-109337862 & $4(4.07)$ & SRTs, GN, PH and HI (10.89) \\
\hline 67. & $\begin{array}{l}\text { MQTL3D.8 } \\
(81.61-83.75)\end{array}$ & IWB54462/IWB65811 & $4(11.40)$ & TN, SRTs, and GN (14.13) \\
\hline 68. & $\begin{array}{l}\text { MQTL3D.9 } \\
(117.71-119.57)\end{array}$ & IWB66928/IWB30266 & $8(3.07)$ & $\begin{array}{l}\text { DTF, GY, GFD, SRTs, and TN } \\
(14.08)\end{array}$ \\
\hline 69. & $\begin{array}{l}\text { MQTL4A.1 } \\
(73.68-74.49)\end{array}$ & Xbcd1975b/XPaggMcgt9 & $18(12.85)$ & $\begin{array}{l}\text { GN, GMRTs, SRTs, DTH, GWei, } \\
\text { and DTM (13.58) }\end{array}$ \\
\hline 70. & $\begin{array}{l}\text { aMQTL4A.2 } \\
(138 . .6-138.91)\end{array}$ & IWB73976/IWB39336 & $6(15.25)$ & SRTs and GWei (24.89) \\
\hline 71. & $\begin{array}{l}\text { MQTL4A.3 } \\
(201.97-202.22)\end{array}$ & Xcdo414/D-1229623 & $10(5.96)$ & $\begin{array}{l}\text { SRTs, GWei, GMRTs, PH and GY } \\
\text { (16.77) }\end{array}$ \\
\hline 72. & \begin{tabular}{|l|} 
MQTL4A.4 \\
$(208.54-209.3)$
\end{tabular} & D-3948044/D-4329293 & $34(4.76)$ & $\begin{array}{l}\text { GWei, SRTs, BY, PH, DTH, GN, } \\
\text { GY, HI, DTM, GMRTs and TN } \\
(18.00)\end{array}$ \\
\hline 73. & $\begin{array}{l}\text { MQTL4A.5 } \\
(221.6-221.66)\end{array}$ & BobWhite_c11327_185/Xfcp532 & $23(5.14)$ & $\begin{array}{l}\text { GWei, GN, SRTs, GY, BY, PH, } \\
\text { GMRTs and TN (14.81) }\end{array}$ \\
\hline 74. & $\begin{array}{l}\text { MQTL4B.1 } \\
(23.15-23.54)\end{array}$ & 1123959|F|0/ACT.CTC7 & $45(15.15)$ & $\begin{array}{l}\text { PH, GMRTs, GWei, DTM, SRTs, } \\
\text { and GY (18.21) }\end{array}$ \\
\hline 75. & $\begin{array}{l}\text { aMQTL4B.2 } \\
(34.44-35.16)\end{array}$ & IWB12274/D-2325366 & $8(19.18)$ & $\begin{array}{l}\text { GMRTs GWei, PH, and DTM } \\
(23.36)\end{array}$ \\
\hline 76. & \begin{tabular}{|l|} 
MQTL4B.3 \\
$(37.75-39.02)$
\end{tabular} & IWB73905/IWB55598 & $3(12.55)$ & GWei (19.49) \\
\hline 77. & $\begin{array}{l}\text { aMQTL } 4 B .4 \\
(47.12-48.28)\end{array}$ & IWA7266/D-1385625 & $3(32.60)$ & SRTs and $\mathrm{PH}(25.60)$ \\
\hline 78. & $\begin{array}{l}{ }^{\mathrm{a} M Q T L} 4 \mathrm{~B} .5 \\
(51.41-51.53)\end{array}$ & wPt-9393/wPt-7365 & $22(17.65)$ & $\begin{array}{l}\text { GWei, SRTs, PH, GN, and DTH } \\
(22.60)\end{array}$ \\
\hline 79. & $\begin{array}{l}\text { MQTL4B.6 } \\
(56.37-56.62)\end{array}$ & Xksm0154/IWB63894 & $44(7.70)$ & $\begin{array}{l}\text { HI, GY, SRTs, GMRTs, GWei, GN, } \\
\text { PH, and DTH (19.79) }\end{array}$ \\
\hline 80. & \begin{tabular}{|l|} 
MQTL4B.7 \\
$(59.28-59.63)$
\end{tabular} & Xmag983/D-4002948 & $27(11.51)$ & $\begin{array}{l}\text { GWei, GN, GY, PH, and SRTs } \\
(25.02)\end{array}$ \\
\hline 81. & $\begin{array}{l}\text { MQTL4B.8 } \\
(74.47-74.52)\end{array}$ & AX-111195232/AX-111625130 & $8(6.78)$ & $\begin{array}{l}\text { GMRTs, SRTs, GWei and PH } \\
(16.03)\end{array}$ \\
\hline 82. & \begin{tabular}{|l|} 
MQTL4D.1 \\
$(7.89-10.06)$
\end{tabular} & AX-109230716/Xbcd1889 & $3(6.93)$ & $\mathrm{PH}(13.65)$ \\
\hline 83. & $\begin{array}{l}\text { aMQTL4D.2 } \\
(27.64-28.96)\end{array}$ & Xbarc359/Xwmc574 & $16(24.40)$ & GMRTs, DTM, and PH (36.83) \\
\hline
\end{tabular}




\begin{tabular}{|c|c|c|c|c|}
\hline 84. & $\begin{array}{l}\text { MQTL4D.3 } \\
\text { (36.82-39.39) }\end{array}$ & | IWB19937/IWB49180 & 9 (22.09) & GWei, PH, and SRTs (24.94) \\
\hline 85. & $\begin{array}{l}\text { MQTL4D.4 } \\
(56.92-60.54)\end{array}$ & IWB15470/IWB18250 & $4(6.07)$ & SRTs, PH, GWei and GN (14.73) \\
\hline 86. & $\begin{array}{l}\text { aMQTL4D.5 } \\
(73.15-74.29)\end{array}$ & Xsrap11a/AX-108975045 & $9(20.92)$ & $\begin{array}{l}\text { PH, GWei, SRTs, HI, GN, and GY } \\
(29.98)\end{array}$ \\
\hline 87. & $\begin{array}{l}\text { MQTL4D.6 } \\
(84.17-84.51)\end{array}$ & AX-109726515/Xsrap11b & $8(10.42)$ & $\begin{array}{l}\text { GY, BY, GMRTs, PH, GN, and HI } \\
(23.65)\end{array}$ \\
\hline 88. & $\begin{array}{l}\text { MQTL4D.7 } \\
(92.37-93.06)\end{array}$ & AX-110418361/AX-95116773 & $5(16.32)$ & $\begin{array}{l}\text { GY, BY, GN, PH and GMRTs } \\
(21.24)\end{array}$ \\
\hline 89. & $\begin{array}{l}\text { aMQTL4D.8 } \\
(94.83-96.12)\end{array}$ & AX-95116773/IWB53820 & $20(18.84)$ & $\begin{array}{l}\text { GWei, PH, SRTs, TN, DTH, GY, } \\
\text { TN, and GN (23.90) }\end{array}$ \\
\hline 90. & $\begin{array}{l}\text { MQTL4D.9 } \\
(102.9-104.25)\end{array}$ & AX-110005953/Xsrap6a & $15(4.54)$ & $\begin{array}{l}\text { SRTs, GMRTs, PH, GY, BY, GN, } \\
\text { and GWei (20.24) }\end{array}$ \\
\hline 91. & $\begin{array}{l}\text { MQTL4D.10 } \\
(125.98-126.4)\end{array}$ & IWB2197/IWA6784 & $5(4.83)$ & GY, BY, and SRTs (15.73) \\
\hline 92. & $\begin{array}{l}\text { MQTL5A.1 } \\
(61.41-62.08)\end{array}$ & IWB586/IWB25701.2 & $19(12.32)$ & $\begin{array}{l}\text { SRTs, GMRTs, GWei, GY, and PH } \\
(15.84)\end{array}$ \\
\hline 93. & $\begin{array}{l}\text { MQTL5A.2 } \\
(110.97-111.43)\end{array}$ & AX-109887759/5AS_1513496_11975 & $71(7.73)$ & $\begin{array}{l}\text { GMRTs, SRTs, TN, PH, GN, DTH, } \\
\text { GWei, GY, DTM, and DTF (18.35) }\end{array}$ \\
\hline 94. & $\begin{array}{l}\text { aMQTL5A.3 } \\
(135.05-135.84)\end{array}$ & Xgpw2249a/D-1150907 & $23(17.65)$ & $\begin{array}{l}\text { PH, DTH, SRTs, HI, GY, GMRTs, } \\
\text { DTF, and TN ( } 21.24)\end{array}$ \\
\hline 95. & $\begin{array}{l}\text { MQTL5A.4 } \\
(175.47-176.15)\end{array}$ & D-1109368/S-988173 & $9(10.71)$ & $\begin{array}{l}\text { GWei, SRTs, DTH, GMRTs and PH } \\
(24.88)\end{array}$ \\
\hline 96. & $\begin{array}{l}\text { MQTL5B.1 } \\
(34.55-36.61)\end{array}$ & Kasp_5B6/Xmag4281 & $12(8.87)$ & $\begin{array}{l}\text { SRTs, DTH, GMRTs GWei, GY, } \\
\text { GN, and TN }(14.41)\end{array}$ \\
\hline 97. & $\begin{array}{l}\text { MQTL5B.2 } \\
(82.1-82.48)\end{array}$ & AX-95249061/Xcdo665b & $10(8.52)$ & $\begin{array}{l}\text { SRTs, GWei, DTF, GMRTs, PH, } \\
\text { and GN (17.64) }\end{array}$ \\
\hline 98. & $\begin{array}{l}\text { aMQTL5B.3 } \\
(87.1-87.86)\end{array}$ & Xfcp428/AX-110503909 & $4(22.72)$ & SRTs, DTH and DTM (21.43) \\
\hline 99. & $\begin{array}{l}\text { MQTL5B.4 } \\
(93.73-93.92)\end{array}$ & Xapr1.5.4/AX-95259005 & $4(7.55)$ & GMRTs, SRTs, HI and GN (13.12) \\
\hline 100. & $\begin{array}{l}\text { MQTL5B.5 } \\
(97.88-98.45)\end{array}$ & XPacgMcgg12/AX-94972602 & $18(6.82)$ & $\begin{array}{l}\text { GMRTs, GY, GWei, BY, PH, and } \\
\text { SRTs (13.27) }\end{array}$ \\
\hline 101. & $\begin{array}{l}\text { MQTL5B.6 } \\
(100.64-103.25)\end{array}$ & CTCG.CAT7/D-1100080 & $5(14.25)$ & $\begin{array}{l}\text { DTH, GMRTs, GWei and SRTs } \\
(14.39)\end{array}$ \\
\hline 102. & \begin{tabular}{|l} 
MQTL5B.7 \\
$(106.5-107.32)$
\end{tabular} & wPt-3439c/S-1076657 & $22(7.75)$ & $\begin{array}{l}\text { GWei, GMRTs, DTH, TN, DTF, } \\
\text { SRTs, and GY (15.89) }\end{array}$ \\
\hline 103. & $\begin{array}{l}\text { MQTL5B.8 } \\
(134.04-134.31)\end{array}$ & Xfba232a/IWB56889 & $5(8.53)$ & $\begin{array}{l}\text { GMRTs, SRTs, BY, and GY } \\
(16.45)\end{array}$ \\
\hline 104. & \begin{tabular}{|l|} 
MQTL5D.1 \\
$(48.72-49.95)$ \\
\end{tabular} & S-1045585/AX-109826869 & $7(4.92)$ & GWei, TN, SRTs, and GY (12.79) \\
\hline 105. & $\begin{array}{l}\text { MQTL5D.2 } \\
(76.31-79.54)\end{array}$ & D-1237279/AX-108840042 & $3(11.48)$ & DTH, GMRTs and GWei (14.76) \\
\hline 106. & $\begin{array}{l}\text { MQTL5D.3 } \\
(93.16-95.14)\end{array}$ & AX-111733701/IWB29163 & $11(6.25)$ & $\begin{array}{l}\text { PH, SRTs, GWei, GMRTs and DTH } \\
(20.41)\end{array}$ \\
\hline 107. & $\begin{array}{l}\text { MQTL5D.4 } \\
(104.66-105.21)\end{array}$ & AX-109314990/AX-111075490 & $16(5.85)$ & $\begin{array}{l}\text { GY, DTF, TN, SRTs, GWei and GN } \\
(15.83)\end{array}$ \\
\hline 108. & $\begin{array}{l}\text { MQTL5D.5 } \\
(115.2-118.51)\end{array}$ & AX-111758247/AX-94469027 & $5(6.16)$ & SRTs and GWei (14.46) \\
\hline 109. & $\begin{array}{l}\text { MQTL6A.1 } \\
(98.34-98.8)\end{array}$ & D-3936250/GENE-4011_91 & $39(7.39)$ & $\begin{array}{l}\text { GN, SRTs, TN, GWei, GMRTs, PH, } \\
\text { GY, and DTH (14.77) }\end{array}$ \\
\hline 110. & \begin{tabular}{|l|} 
MQTL6A.2 \\
$(108.95-109.74)$ \\
\end{tabular} & P78/M87.7/wPt-3191a & $27(6.44)$ & $\begin{array}{l}\text { GWei, PH, SRTs, GMRTs, GN, HI, } \\
\text { GY, and DTH (17.21) }\end{array}$ \\
\hline 111. & \begin{tabular}{|l|} 
MQTL6A.3 \\
$(150.19-151.48)$
\end{tabular} & D-1124675/D-1076799 & $5(6.96)$ & $\begin{array}{l}\text { GN, SRTs, GMRTs and DTH } \\
(14.45)\end{array}$ \\
\hline 112. & \begin{tabular}{|l|} 
MQTL6B.1 \\
$(45.07-47.28)$
\end{tabular} & XPaagMctg3/AGC.TGC3 & $4(4.81)$ & $\begin{array}{l}\text { GWei, DTH, DTM, and SRTs } \\
(14.25)\end{array}$ \\
\hline
\end{tabular}




\begin{tabular}{|c|c|c|c|c|}
\hline 113. & $\begin{array}{l}\text { MQTL6B.2 } \\
(99.38-100.75)\end{array}$ & ACT.CAT2/P8966.1 & $10(4.46)$ & $\begin{array}{l}\text { DTF, GMRTs, SRTs, GY, DTH, } \\
\text { DTF and GWei (20.73) }\end{array}$ \\
\hline 114. & $\begin{array}{l}\text { MQTL6B.3 } \\
(105.2-107.05)\end{array}$ & P8444.1/Xksm45 & $4(6.40)$ & GMRTs, GWei, and PH (12.12) \\
\hline 115. & $\begin{array}{l}\text { MQTL6B.4 } \\
(112.61-115.42)\end{array}$ & D-379317/AGG.CAG5 & $8(5.61)$ & $\begin{array}{l}\text { GY, GMRTs, DTH, GWei, HI, and } \\
\text { SRTs (13.67) }\end{array}$ \\
\hline 116. & $\begin{array}{l}\text { MQTL6B.5 } \\
(116.45-116.99)\end{array}$ & AGG.CAG5/APaagMcgc1 & $2(12.97)$ & SRTs $(27.48)$ \\
\hline 117. & $\begin{array}{l}\text { MQTL6B.6 } \\
(118.99-119.39)\end{array}$ & AGG.CAG5/APaagMcgc1 & $2(15.51)$ & GWei and $\mathrm{PH}(14.41)$ \\
\hline 118. & $\begin{array}{l}\text { MQTL6B.7 } \\
(121.38-121.71)\end{array}$ & AGG.CAG5/IWB67309.2 & $3(8.80)$ & GMRTs, SRTs and GWei (16.73) \\
\hline 119. & $\begin{array}{l}\text { MQTL6B.8 } \\
(123.2-123.74)\end{array}$ & IWB67309.2/AX-94465053 & $13(6.44)$ & $\begin{array}{l}\text { GMRTs, SRTs, TN, GWei, PH, and } \\
\text { DTM (14.69) }\end{array}$ \\
\hline 120. & $\begin{array}{l}\text { MQTL6B.9 } \\
(128.28-128.56)\end{array}$ & Xgdm136/IWA860 & $14(12.26)$ & $\begin{array}{l}\text { GMRTs, GN, GY, GWei, SRTs, and } \\
\text { DTH (19.03) }\end{array}$ \\
\hline 121. & $\begin{array}{l}\text { MQTL6B.10 } \\
(151.56-202.28)\end{array}$ & IWB60027/XPaggMcat5 & $2(5.45)$ & SRTs and GMRTs (11.05) \\
\hline 122. & $\begin{array}{l}\text { MQTL6D.1 (0- } \\
\text { 2.78) }\end{array}$ & IWB59376.2/IWB36391 & $2(5.29)$ & GWei and SRTs (11.00) \\
\hline 123. & $\begin{array}{l}\text { MQTL6D.2 } \\
(8.62-11.11)\end{array}$ & S-3953435/1127306| F| 0 & $3(5.03)$ & SRTs (15.90) \\
\hline 124. & $\begin{array}{l}\text { MQTL6D.3 } \\
(13.58-14.37)\end{array}$ & AX-111501437/6DL_3297209_3422 & $2(3.04)$ & SRTs (12.13) \\
\hline 125. & \begin{tabular}{|l|} 
MQTL6D.4 \\
$(31.81-35.57)$ \\
\end{tabular} & AX-94493103/IWA1967.2 & $8(4.02)$ & $\begin{array}{l}\text { BY, GY, PH, GN, SRTs, and TN } \\
(14.58)\end{array}$ \\
\hline 126. & $\begin{array}{l}\text { aMQTL6D.5 } \\
(42.88-43.58)\end{array}$ & IWA6361/AX-110007215 & $3(14.05)$ & GWei and GY (20.73) \\
\hline 127. & $\begin{array}{l}\text { MQTL6D.6 } \\
(62.74-63.7)\end{array}$ & Xwmc773/AX-109007320 & $4(5.90)$ & GY, GWei, SRTs and PH (12.78) \\
\hline 128. & $\begin{array}{l}\text { MQTL7A.1 } \\
(108.08-109.57)\end{array}$ & IWB7950/XgbxG564a & $39(5.98)$ & $\begin{array}{l}\text { DTH, GWei, DTF, DTM, TN, SRTs, } \\
\text { GMRTs, GN, and HI (14.52) }\end{array}$ \\
\hline 129. & \begin{tabular}{|l|} 
MQTL7A.2 \\
$(125.78-126.93)$ \\
\end{tabular} & 7AS_4114596_204/7AS_4045514_1450 & $18(10.63)$ & $\begin{array}{l}\text { HI, GY, DTH, SRTs, GMRTs, } \\
\text { GWei, TN, GN, and PH (19.45) }\end{array}$ \\
\hline 130. & $\begin{array}{l}\text { MQTL7A.3 } \\
(155.23-155.25)\end{array}$ & IWB207/7AS_4183259_787 & $31(7.21)$ & $\begin{array}{l}\text { DTF, TN, SRTs, GY, BY, GN, } \\
\text { GWei, GMRTs and PH (19.32) }\end{array}$ \\
\hline 131. & $\begin{array}{l}\text { MQTL7B.1 } \\
(38.69-40.06)\end{array}$ & CTCG.CAT2/AGT.CAGT6 & $24(7.42)$ & $\begin{array}{l}\text { DTH, DTM, GY, GWei, PH, SRTs, } \\
\text { GN, HI and BY (19.33) }\end{array}$ \\
\hline 132. & $\begin{array}{l}\text { MQTL7B.2 } \\
(57.37-58.16)\end{array}$ & AX-108740562/S13M23.195 & $32(4.02)$ & $\begin{array}{l}\text { SRTs, DTM, BY, GWei, DTH, } \\
\text { GMRTs, DTF, BGY, PH, GN and } \\
\text { HI (16.13) }\end{array}$ \\
\hline 133. & $\begin{array}{l}\text { MQTL7B.3 } \\
(68.78-69.63) \\
\end{array}$ & S-1130473/wPt-4673 & $8(6.58)$ & DTF, HI, GN, GY and DTF (19.86) \\
\hline 134. & $\begin{array}{l}\text { MQTL7B.4 } \\
(76.76-77.69)\end{array}$ & D-3021954/Xpsr687 & $\begin{array}{l}7 \\
(7.59) \\
\end{array}$ & $\begin{array}{l}\text { GN, DTM, GMRTs, GY, and SRTs } \\
(16.75)\end{array}$ \\
\hline 135. & \begin{tabular}{|l|} 
MQTL7B.5 \\
$(106.11-107.89)$ \\
\end{tabular} & Xwmc707/Xfbb258 & $8(5.84)$ & $\begin{array}{l}\text { GMRTs, SRTs, GWei, and TN } \\
(18.73)\end{array}$ \\
\hline 136. & \begin{tabular}{|l|} 
MQTL7B.6 \\
$(236.54-236.79)$ \\
\end{tabular} & IWB68803/XPaagMcgc11 & $2(5.39)$ & GY and BY (10.68) \\
\hline 137. & $\begin{array}{l}\text { MQTL7D.1 } \\
(7.29-11.22)\end{array}$ & IWB517/Xgwm735b & $4(4.38)$ & GFD, PH, GY, and GWei (15.19) \\
\hline 138. & \begin{tabular}{|l|} 
MQTL7D.2 \\
$(75.17-76.77)$
\end{tabular} & Xswes940.3/IWB17494 & $15(8.85)$ & $\begin{array}{l}\text { SRTs, GY, BY, HI, DTM, DTF, } \\
\text { GMRTs, GWei, and PH (19.49) }\end{array}$ \\
\hline 139. & $\begin{array}{l}\text { MQTL7D.3 } \\
(82.59-85.56)\end{array}$ & IWB50283/IWB12642.2 & $13(9.00)$ & $\begin{array}{l}\text { GMRTs, SRTs, GN, GY, and DTM } \\
(21.32)\end{array}$ \\
\hline 140. & $\begin{array}{l}\text { MQTL7D.4 } \\
(96.65-100.15)\end{array}$ & D-2247427/Xwmc42 & $8(4.58)$ & GMRTs and SRTs (44.55) \\
\hline 141. & MQTL7D.5 & Xpsp3123/Xswes558.1 & 6 & GMRTs and DTM (20.70) \\
\hline
\end{tabular}


a‘Breeder's MQTLs' selected based on the criteria given by Löffler et al. (2009).

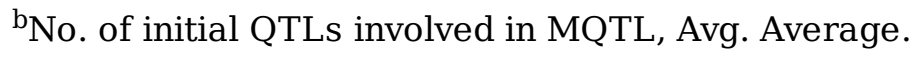

Table 3 Ortho-MQTLs in barley, rice and maize based on the syntenic region with wheat MQTLs 


\begin{tabular}{|c|c|c|c|c|}
\hline $\begin{array}{l}\text { Sr. } \\
\text { no. }\end{array}$ & $\begin{array}{l}\text { Ortho- } \\
\text { MQTL }\end{array}$ & $\begin{array}{l}\text { Wheat } \\
\text { MQTL } \\
\text { (genomic } \\
\text { position in } \\
\text { Mb) }\end{array}$ & Original MQTL name (chr., genomic position in $\mathrm{Mb}$ ) & Reference \\
\hline 1. & $\begin{array}{l}\text { ortho- } \\
\text { MQTL1A.8 }\end{array}$ & $\begin{array}{l}\text { MQTL1A.8 } \\
(12.11- \\
54.01)\end{array}$ & $\begin{array}{l}\text { Barley: Nil } \\
\text { Rice: MQTL-GW17 (5, 0.94-1.29); MQTL-HD12 (5, 21.14-27.80) } \\
\text { Maize: MQTL17 (3,95.27-107.57); MQTL36 (3,90.04-118.17); } \\
\text { MQTL-17 (3, 7.67-10.08); MQTL-39 (6, 0.5 21.9) }\end{array}$ & $\begin{array}{l}\text { Chen et } \\
\text { al. (2017); } \\
\text { Khahani et } \\
\text { al. (2020); } \\
\text { Wang et al. } \\
\text { (2013, } \\
\text { 2016); }\end{array}$ \\
\hline 2. & $\begin{array}{l}\text { ortho- } \\
\text { MQTL1B.5 }\end{array}$ & $\begin{array}{l}\text { MQTL1B.5 } \\
(17.34- \\
17.38)\end{array}$ & $\begin{array}{l}\text { Barley: Nil } \\
\text { Rice: Nil } \\
\text { Maize: MQTL65 (6, 36.55-89.17); MQTL-41 (6, 36.56-89.15); } \\
\text { MQTL45 (8, 73.70-95.02); MQTL84 (8, 73.22-95.76) }\end{array}$ & $\begin{array}{l}\text { Chen et al. } \\
\text { (2017); } \\
\text { Wang et al. } \\
(2013, \\
2016)\end{array}$ \\
\hline 3. & $\begin{array}{l}\text { ortho- } \\
\text { MQTL1B.6 }\end{array}$ & $\begin{array}{l}\text { MQTL1B.6 } \\
(12.81- \\
13.24)\end{array}$ & $\begin{array}{l}\text { Barley: Nil } \\
\text { Rice: Nil } \\
\text { Maize: MQTL37 (3, 125.71-136.45); MQTL-20 (3, 86.75-136.09) }\end{array}$ & $\begin{array}{l}\text { Chen et al. } \\
(2017) ; \\
\text { Wang et al. } \\
(2016)\end{array}$ \\
\hline 4. & $\begin{array}{l}\text { ortho- } \\
\text { MQTL2B.3 }\end{array}$ & $\begin{array}{l}\text { MQTL2B.3 } \\
(28.37- \\
29.99)\end{array}$ & $\begin{array}{l}\text { Barley: MQTL2H.1 (2H, 28.25-41.95) } \\
\text { Rice: MQTL-HD9 (4, 2.08-6.98) } \\
\text { Maize: MQTL12 (2,154.64-174.69); MQTL24 (2, 152.70-175.81); } \\
\text { MQTL-11 (2,154.53-177.65); MQTL13 (2, 192.59-201.8); MQTL26 } \\
\text { (4,198.38-225.80); MQTL51 (4, 198.68-234.16); MQTL54 (5, 1.54- } \\
\text { 2.02); MQTL29 (5,14.11-29.39); MQTL57 (10, 14.86-77.02); } \\
\text { mQTL10-2 (5, 16.15-31.71); MQTL107(10, 42.26-87.32); } \\
\text { MQTL108 (10, 95.27-109.08); MQTL-70 (10, 85.27-102.52) }\end{array}$ & $\begin{array}{l}\text { Chen et al. } \\
(2017) ; \\
\text { Khahani et } \\
\text { al. (2019, } \\
2020) ; \\
\text { Wang et al. } \\
(2013 \text {, } \\
\text { 2016); } \\
\text { Zhao et al. } \\
(2018)\end{array}$ \\
\hline 5. & $\begin{array}{l}\text { ortho- } \\
\text { MQTL2B.5 }\end{array}$ & $\begin{array}{l}\text { MQTL2B.5 } \\
(7.11- \\
30.49)\end{array}$ & $\begin{array}{l}\text { Barley: Nil } \\
\text { Rice: MQTL-GW14 (4, 15.74-18.44); MQTL-PH15 (4, 20.56-23.90); } \\
\text { MQTL-PH20 (7, 12.78-14.95); MQTL-HD15 (7, 12.78-14.95) } \\
\text { Maize: MQTL11 (2, 43.63-100.18); mQTL2-2 (2, 21.78-61.80); } \\
\text { MQTL18 (4, 9.54-14.47); mQTL5-2 (5, 135.81-168.13) }\end{array}$ & $\begin{array}{l}\text { Khahani et } \\
\text { al. (2020); } \\
\text { Wang et al. } \\
(2013) ; \\
\text { Zhao et al. } \\
\text { (2018) }\end{array}$ \\
\hline 6. & $\begin{array}{l}\text { ortho- } \\
\text { MQTL2B.6 }\end{array}$ & \begin{tabular}{l|} 
MQTL2B.6 \\
$(7.77-$ \\
$11.08)$
\end{tabular} & \begin{tabular}{|l} 
Barley: Nil \\
Rice: MQTL-HD9 (4, 2.08-6.98); MQTL-PH16 (4, 30.63-33.12) \\
Maize: MQTL27 (2, 202.93-210.5); MQTL-14 (2, 209.83-211.52); \\
MQTL26 (4,198.37-225.80); MQTL51 (4, 198.68-234.17); MQTL- \\
37 (5, 188.65-193.45); mQTL10-2 (10, 14.86-77.02)
\end{tabular} & $\begin{array}{l}\text { Chen et al. } \\
(2017) ; \\
\text { Khahani et } \\
\text { al. (2020); } \\
\text { Wang et al. } \\
(2013 \text {, } \\
\text { 2016); Zhao } \\
\text { et al. (2018) }\end{array}$ \\
\hline 7. & $\begin{array}{l}\text { ortho- } \\
\text { MQTL2D.5 }\end{array}$ & $\begin{array}{l}\text { MQTL2D.5 } \\
(14.36- \\
88.35)\end{array}$ & $\begin{array}{l}\text { Barley: MQTL2H.1 2H (2H, 28.25-41.95) } \\
\text { Rice: Nil } \\
\text { Maize: MQTL21 (2, 14.79-20.08); MQTL13 (2, 192.59-201.8); } \\
\text { MQTL-13 (2, 199.17-205.84); MQTL46 (4, 42.17-75-57); MQTL-27 } \\
\text { (4, 39.32-144.04); MQTL-69 (10,13.06-24.61); mQTL10-2 (10, } \\
\text { 14.86-77.02); MQTL107 (10, 42.26-87.32) }\end{array}$ & $\begin{array}{l}\text { Chen et al. } \\
(2017) ; \\
\text { Khahani et } \\
\text { al. (2019); } \\
\text { Wang et al. } \\
(2013 \text {, } \\
\text { 2016); Zhao } \\
\text { et al. (2018) }\end{array}$ \\
\hline 8. & $\begin{array}{l}\text { ortho- } \\
\text { MQTL2D.6 }\end{array}$ & $\begin{array}{l}\text { MQTL2D.6 } \\
(14.90- \\
21.06)\end{array}$ & $\begin{array}{l}\text { Barley: Nil } \\
\text { Rice: MQTL-HD9 (4, 2.08-6.98); MQTL-GW15 (4, 23.43-24.49) } \\
\text { Maize: MQTL11 (2,43.63-100.17); MQTL23 (2, 70.33-149.74); } \\
\text { MQTL-10 (2, 62.92-149.11); MQTL47 (4, 146.39-154.56); MQTL22 } \\
\text { (4,157.61-166.91); mQTL4-2 (4, 153.69-171.70); MQTL26 (4, } \\
\text { 198.37-225.80); MQTL51 (4, 198.68-234.17); MQTL60 (5, 159.12- } \\
\text { 168.29); MQTL-36 (5, 162.84-167.47); mQTL5-2 (5, 135.81-168.13); } \\
\text { MQTL62 (5, 202.86-207.78); MQTL-38 (5, 205.44-207.73); mQTL5- } \\
\text { 4 (5, 205.44-217.01); MQTL108 (10, 95.27-109.08); MQTL-70 (10, } \\
\text { 85.27-102.52) }\end{array}$ & $\begin{array}{l}\text { Chen et al. } \\
\text { (2017); } \\
\text { Khahani et } \\
\text { al. (2020); } \\
\text { Wang et al. } \\
\text { (2013, } \\
\text { 2016); } \\
\text { Zhao et al. } \\
\text { (2018) }\end{array}$ \\
\hline 9. & $\begin{array}{l}\text { ortho- } \\
\text { MQTL2D.7 }\end{array}$ & MQTL2D.7 & $\begin{array}{l}\text { Barley: Nil } \\
\text { Rice: MQTL-HD9 }(4,2.08-6.98)\end{array}$ & $\begin{array}{l}\text { Chen et al. } \\
\text { (2017); }\end{array}$ \\
\hline
\end{tabular}




\begin{tabular}{|c|c|c|c|c|}
\hline & & $\begin{array}{l}(23.42- \\
25.04)\end{array}$ & $\begin{array}{l}\text { Maize: MQTL11 (2, 43.63-100.18); MQTL23 (2, 70.33-149.75); } \\
\text { MQTL-10 (2, 62.92-149.11); MQTL-27 (4, 39.32-144.04); MQTL59 } \\
(5,76.25-137.57)\end{array}$ & $\begin{array}{l}\text { Khahani et } \\
\text { al. (2020); } \\
\text { Wang et al. } \\
\text { (2013, } \\
\text { 2016) }\end{array}$ \\
\hline 10. & $\begin{array}{l}\text { ortho- } \\
\text { MQTL3A.5 }\end{array}$ & $\begin{array}{l}\text { MQTL3A.5 } \\
(21.22- \\
30.56)\end{array}$ & $\begin{array}{l}\text { Barley: Nil } \\
\text { Rice: Nil } \\
\text { Maize: MQTL16 (3, 11.67-29.84); MQTL83 (8, 10.85-20.83) }\end{array}$ & $\begin{array}{l}\text { Wang et al. } \\
(2013, \\
2016)\end{array}$ \\
\hline 11. & $\begin{array}{l}\text { ortho- } \\
\text { MQTL3A.7 }\end{array}$ & $\begin{array}{l}\text { MQTL3A.7 } \\
(17.6-19.6)\end{array}$ & $\begin{array}{l}\text { Barley: Nil } \\
\text { Rice: Nil } \\
\text { Maize: MQTL16 (3, 11.67-29.84); MQTL83 (8, 10.85-20.83) }\end{array}$ & $\begin{array}{l}\text { Wang et al. } \\
\text { (2013, } \\
\text { 2016) }\end{array}$ \\
\hline 12. & $\begin{array}{l}\text { ortho- } \\
\text { MQTL4A.3 }\end{array}$ & $\begin{array}{l}\text { MQTL4A.3 } \\
(709.90- \\
713.52)\end{array}$ & $\begin{array}{l}\text { Barley: MQTL4H.6 (4H, 632.20-641.09) } \\
\text { Rice: MQTL-HD5 (3, 1.03-1.66); MQTL-TN4 (3, 7.23-9.31); MQTL- } \\
\text { GW10 (3, 9.49-11.30); MQTL-YLD8 (3, 9.24-10.39); MQTL-GW32 } \\
\text { (11,5.37-8.10); MQTL-GW10 (3, 9.49-11.30); MQTL-YLD8 (3, 9.24- } \\
\text { 10.39); MQTL-GW32 (11, 5.37-8.10) } \\
\text { Maize: MQTL3 (1, 34.78-44.14); MQTL6 (1, 37.47-40.20); mQTL1- } \\
\text { 3 (1,14.79-43.06); mQTL5-2 (5, 135.81-168.13); MQTL59 (5, } \\
\text { 76.25-137.57); MQTL-35 (5, 78.36-123.21); MQTL-66 (9, 120.2- } \\
\text { 133.6); mQTL9-3 (9, 120.65-135.91) }\end{array}$ & $\begin{array}{l}\text { Chen et al. } \\
\text { (2017); } \\
\text { Khahani et } \\
\text { al. (2019, } \\
\text { 2020); } \\
\text { Wang et al. } \\
\text { (2013, } \\
\text { 2016); Zhao } \\
\text { et al. (2018) }\end{array}$ \\
\hline 13. & $\begin{array}{l}\text { ortho- } \\
\text { MQTL4B.1 }\end{array}$ & $\begin{array}{l}\text { MQTL4B.1 } \\
(0.62-7.04)\end{array}$ & $\begin{array}{l}\text { Barley: MQTL4H.1 (4H, 2.26-8.72) } \\
\text { Rice: MQTL-TN4 (3, 7.23-9.31); MQTL-YLD19 (11, 9.06-14.95) } \\
\text { Maize: MQTL1-3 (1, 14.79-43.06); mQTL1-4 (1,148.62-191.47); } \\
\text { mQTL1-7 (1, 258.87-290.14); MQTL29 (5, 14.11-29.39); MQTL57 } \\
\text { (5,16.15-31.71); mQTL1-4 (1,148.62-191.47); mQTL1-7 (1, } \\
\text { 258.87-290.14); MQTL29 (5, 14.11-29.39); MQTL57 (5, 16.15- } \\
\text { 31.71) }\end{array}$ & $\begin{array}{l}\text { Khahani et } \\
\text { al. (2019, } \\
\text { 2020); } \\
\text { Wang et al. } \\
\text { (2013, } \\
\text { 2016); Zhao } \\
\text { et al. (2018) } \\
\end{array}$ \\
\hline 14. & $\begin{array}{l}\text { ortho- } \\
\text { MQTL4B.5 }\end{array}$ & $\begin{array}{l}\text { MQTL4B.5 } \\
(13.05- \\
14.90)\end{array}$ & $\begin{array}{l}\text { Barley: MQTL4H.1 (4H, 2.26-8.72) } \\
\text { Rice: MQTL-GW13 (3, 30.10-30.38) } \\
\text { Maize: MQTL16 (1,214.97-224.20); mQTL1-5 (1, 209.51-, 233.37); } \\
\text { MQTL8 (1, 256.34-262.95); mQTL1-6 (1, 257.38-269.96); MQTL29 } \\
(5,14.11-29.39)\end{array}$ & $\begin{array}{l}\text { Khahani et } \\
\text { al. (2019, } \\
2020) ; \\
\text { Wang et al. } \\
\text { (2013, } \\
\text { 2016); Zhao } \\
\text { et al. (2018) }\end{array}$ \\
\hline 15. & $\begin{array}{l}\text { ortho- } \\
\text { MQTL4B.7 }\end{array}$ & $\begin{array}{l}\text { MQTL4B.7 } \\
\text { (605.16- } \\
619.07)\end{array}$ & $\begin{array}{l}\text { Barley: Nil } \\
\text { Rice: MQTL-PH11 (3, 1.66-2.48); MQTL-YLD19 (11, 9.06-14.95) } \\
\text { Maize: MQTL6 (1, 80.18-93.0); MQTL62 (5, 202.86-207.78) }\end{array}$ & $\begin{array}{l}\text { Khahani et } \\
\text { al. (2020); } \\
\text { Wang et al. } \\
(2013 \text {, } \\
\text { 2016) }\end{array}$ \\
\hline 16. & $\begin{array}{l}\text { ortho- } \\
\text { MQTL5A.2 }\end{array}$ & $\begin{array}{l}\text { MQTL5A.2 } \\
(10.84- \\
17.53)\end{array}$ & $\begin{array}{l}\text { Barley: Nil } \\
\text { Rice: MQTL-PH28 (12, 22.45-23.06) } \\
\text { Maize: MQTL26 (4, 198.37-225.80); MQTL51 (4, 198.68-234.17) }\end{array}$ & $\begin{array}{l}\text { Khahani et } \\
\text { al. (2020); } \\
\text { Wang et al. } \\
(2013 \text {, } \\
2016)\end{array}$ \\
\hline 17. & $\begin{array}{l}\text { ortho- } \\
\text { MQTL5A.3 }\end{array}$ & $\begin{array}{l}\text { MQTL5A.3 } \\
(11.05- \\
403.72)\end{array}$ & $\begin{array}{l}\text { Barley: MQTL5H.1 (5H, 178.37-248.57) } \\
\text { Rice: Nil } \\
\text { Maize: MQTL20 (4, 31.32-42.02); MQTL-27 (4, 39.32-144.04); } \\
\text { mQTL4-1 (4, 32.24-46.45); MQTL22 (4, 157.61-166.91); MQTL48 } \\
\text { (4, 162.92-174.12); mQTL4-2 (4, 153.69-171.70) }\end{array}$ & $\begin{array}{l}\text { Chen et al. } \\
(2017) ; \\
\text { Khahani et } \\
\text { al. (2019); } \\
\text { Wang et al. } \\
\text { (2013); } \\
\text { Zhao et al. } \\
\text { (2018) }\end{array}$ \\
\hline 18. & $\begin{array}{l}\text { ortho- } \\
\text { MQTL5B.7 }\end{array}$ & $\begin{array}{l}\text { MQTL5B.7 } \\
(13.72- \\
15.05)\end{array}$ & $\begin{array}{l}\text { Barley: Nil } \\
\text { Rice: MQTL-PH28 (12, 22.45-23.06) } \\
\text { Maize: MQTL19 }(4,17.42-20.51)\end{array}$ & $\begin{array}{l}\text { Khahani et } \\
\text { al. (2019, } \\
2020) \text {; } \\
\text { Wang et al. } \\
\text { (2013) }\end{array}$ \\
\hline 19. & $\begin{array}{l}\text { ortho- } \\
\text { MQTL6A.1 }\end{array}$ & $\begin{array}{l}\text { MQTL6A.1 } \\
\text { (555.67- } \\
563.51)\end{array}$ & $\begin{array}{l}\text { Barley: Nil } \\
\text { Rice: Nil } \\
\text { Maize: MQTL12 (2, 154.64-174.69); MQTL24 (2, 152.70-175.81); } \\
\text { MQTL-11 (2,154.53-177.65); MQTL23 (4, 173.32-181.39); MQTL49 } \\
\text { (4, 179.77-182.35); mQTL5-4 (5, 205.44-217.01) }\end{array}$ & $\begin{array}{l}\text { Chen et al. } \\
(2017) ; \\
\text { Wang et al. } \\
(2013 \text {, } \\
\text { 2016); Zhao } \\
\text { et al. (2018) }\end{array}$ \\
\hline 20. & $\begin{array}{l}\text { ortho- } \\
\text { MQTL6A.2 }\end{array}$ & $\begin{array}{l}\text { MQTL6A.2 } \\
\text { (25.63- } \\
55.57)\end{array}$ & $\begin{array}{l}\text { Barley: Nil } \\
\text { Rice: MQTL-GW6 }(2,9.56-11.75) \\
\text { Maize: MQTL51 }(4,198.68-234.17)\end{array}$ & $\begin{array}{l}\text { Khahani et } \\
\text { al. (2020); }\end{array}$ \\
\hline
\end{tabular}




\begin{tabular}{|c|c|c|c|c|}
\hline & & & & $\begin{array}{l}\text { Wang et al. } \\
(2016)\end{array}$ \\
\hline 21. & $\begin{array}{l}\text { ortho- } \\
\text { MQTL7A.1 }\end{array}$ & $\begin{array}{l}\text { MQTL7A.1 } \\
(3.21-8.26)\end{array}$ & $\begin{array}{l}\text { Barley: Nil } \\
\text { Rice: MQTL-PH23 (8, 6.03-8.68); MQTL-GW25 (8, 5.80-8.15); } \\
\text { MQTL-YLD16 (8, 11.58-17.51) } \\
\text { Maize: MQTL48 (9, 26.82-28.44); mQTL9-2 (9, 26.96-105.50) }\end{array}$ & $\begin{array}{l}\text { Khahani et } \\
\text { al. (2020); } \\
\text { Wang et al. } \\
\text { (2013); } \\
\text { Zhao et al. } \\
\text { (2018) }\end{array}$ \\
\hline 22. & $\begin{array}{l}\text { ortho- } \\
\text { MQTL7A.3 }\end{array}$ & $\begin{array}{l}\text { MQTL7A.3 } \\
\text { (44.45- } \\
47.03)\end{array}$ & $\begin{array}{l}\text { Barley: MQTL7H.2 (7H, 21.73-24.48) } \\
\text { Rice: MQTL-HD13 (6, 1.64-2.36) } \\
\text { Maize: MQTL92 (9, 5.79-9.59); MQTL47 (9, 16.66-22.11); MQTL93 } \\
\text { (9, 17.75-23.89); MQTL-64 (9,19.2-22.68); MQTL95 (9, 43.84- } \\
\text { 87.99); mQTL9-2 (9, 26.96-105.50) }\end{array}$ & $\begin{array}{l}\text { Chen et al. } \\
\text { (2017); } \\
\text { Khahani et } \\
\text { al. (2020); } \\
\text { Wang et al. } \\
\text { (2013, } \\
\text { 2016); Zhao } \\
\text { et al. (2018) }\end{array}$ \\
\hline 23. & $\begin{array}{l}\text { ortho- } \\
\text { MQTL7B.1 }\end{array}$ & $\begin{array}{l}\text { MQTL7B.1 } \\
(3.70-6.37)\end{array}$ & $\begin{array}{l}\text { Barley: MQTL7H.3 (7H, 34.08-38.12) } \\
\text { Rice: MQTL-HD19 (8, 4.17-5.42) } \\
\text { Maize: MQTL47 (9, 16.66-22.11); MQTL93 (9, 17.75-23.89); } \\
\text { mQTL9-1 (9, 16.24-19.09) }\end{array}$ & $\begin{array}{l}\text { Khahani et } \\
\text { al. (2019, } \\
\text { 2020); } \\
\text { Wang et al. } \\
\text { (2013; } \\
\text { 2016); Zhao } \\
\text { et al. (2018) }\end{array}$ \\
\hline 24. & \begin{tabular}{|l} 
ortho- \\
MQTL7B.2
\end{tabular} & $\begin{array}{l}\text { MQTL7B.2 } \\
\text { (18.10- } \\
44.62)\end{array}$ & $\begin{array}{l}\text { Barley: Nil } \\
\text { Rice: MQTL-YLD14 (6, 27.37-29.62) } \\
\text { Maize: MQTL46 (9, 14.14-18.04) }\end{array}$ & $\begin{array}{l}\text { Khahani et } \\
\text { al. (2020); } \\
\text { Wang et al. } \\
(2013)\end{array}$ \\
\hline
\end{tabular}

Table 4 Wheat homologues of rice, barley and maize yield-related genes in MQTL regions 


\begin{tabular}{|c|c|c|c|c|}
\hline $\begin{array}{l}\text { Sr. } \\
\text { no. }\end{array}$ & $\begin{array}{l}\text { Gene } \\
\text { (associated } \\
\text { trait) }\end{array}$ & Gene product & $\begin{array}{l}\text { Wheat homologues } \\
\text { (corresponding MQTL) }\end{array}$ & References \\
\hline \multicolumn{5}{|c|}{ Rice } \\
\hline 1. & ${ }^{\mathrm{a}} A n-1(\mathrm{GS}, \mathrm{GN})$ & $\begin{array}{l}\text { helix-loop-helix DNA binding domain } \\
\text { protein }\end{array}$ & $\begin{array}{l}\text { TraesCS2A02G275600 } \\
\text { (MQTL2A.2), } \\
\text { TraesCS2D02G274600 } \\
\text { (MQTL2D.8) }\end{array}$ & $\begin{array}{l}\text { Luo et al. } \\
(2013)\end{array}$ \\
\hline 2. & $\begin{array}{l}\left.{ }_{\mathrm{a}}^{\mathrm{B}} \mathrm{Bsg}\right) \\
\mathrm{GY}(\mathrm{PH}, \mathrm{FD}\end{array}$ & $\begin{array}{l}\text { protein of unknown function (DUF640 } \\
\text { domain containing protein) }\end{array}$ & $\begin{array}{l}\text { TraesCS6D02G361900 } \\
\text { (MQTL6D.1) }\end{array}$ & $\begin{array}{l}\text { Yan et al. } \\
(2013)\end{array}$ \\
\hline 3. & ${ }^{\mathrm{a}} \mathrm{D} 11(\mathrm{GL})$ & cytochrome P450 & $\begin{array}{l}\text { TraesCS2D02G331100 } \\
\text { (MQTL2D.8) }\end{array}$ & $\begin{array}{l}\text { Tanabe et al. } \\
(2005)\end{array}$ \\
\hline 4. & ${ }^{\mathrm{a}} \mathrm{D} 2(\mathrm{GL})$ & cytochrome P450 & $\begin{array}{l}\text { TraesCS3A02G103800 } \\
\text { (MQTL3A.3), } \\
\text { TraesCS3D02G106100 } \\
\text { (MQTL3D.6) }\end{array}$ & $\begin{array}{l}\text { Hong et al. } \\
(2003)\end{array}$ \\
\hline 5. & $D E P 1(\mathrm{PA}, \mathrm{PE})$ & $\begin{array}{l}\text { phosphatidylethanolamine-binding } \\
\text { protein (PEBP) like domain protein }\end{array}$ & $\begin{array}{l}\text { DEP1-5A (MQTL5A.4), DEP1- } \\
\text { 5D (MQTL5D.5) }\end{array}$ & $\begin{array}{l}\text { Sun et al. } \\
(2014)\end{array}$ \\
\hline 6. & GIF1 (GF) & cell-wall invertase & TaCwi-A1 (MQTL2A.2) & $\begin{array}{l}\text { Wang et al. } \\
\text { (2008) }\end{array}$ \\
\hline 7. & GS3 (GS) & $\begin{array}{l}\text { protein having } 3 \text { domains viz., } \\
\text { transmembrane region, a TNFR/NGFR } \\
\text { family cysteine-rich domain and a von } \\
\text { Willebrand factor type C }\end{array}$ & $\begin{array}{l}\text { TaGS-D1, } \\
\text { TraesCS7A02G017700 } \\
\text { (MQTL7A.1) }\end{array}$ & $\begin{array}{l}\text { Mao et al. } \\
(2010)\end{array}$ \\
\hline 8. & $\begin{array}{l}\text { GW2 (GW, } \\
\text { GWei) }\end{array}$ & $\begin{array}{l}\text { RING-type protein with E3 ubiquitin } \\
\text { ligase }\end{array}$ & $\begin{array}{l}\text { TaGW-A2 (MQTL6A.2), } \\
\text { TraesCS6B02G215300 } \\
\text { (MQTL6B.10) }\end{array}$ & $\begin{array}{l}\text { Song et al. } \\
(2007)\end{array}$ \\
\hline 9. & OsSPL14 (PB) & $\begin{array}{l}\text { squamosa promter-binding-like } \\
\text { transcription activator }\end{array}$ & $\begin{array}{l}\text { TraesCS5D02G273900 } \\
\text { (MQTL5D.3, MQTL5D.5) }\end{array}$ & $\begin{array}{l}\text { Miura et al. } \\
(2010)\end{array}$ \\
\hline 10. & ${ }^{\mathrm{a}} L P(\mathrm{PL})$ & $\begin{array}{l}\text { remorin, C-terminal region domain } \\
\text { containing protein }\end{array}$ & $\begin{array}{l}\text { TraesCS5D02G244300 } \\
\text { (MQTL5D.3, MQTL5D.5) }\end{array}$ & $\begin{array}{l}\text { Liu et al. } \\
(2016)\end{array}$ \\
\hline 11. & $\begin{array}{l}\text { a } P G L 1(\mathrm{GL}, \\
\text { GWei) }\end{array}$ & $\begin{array}{l}\text { similar to DNA-binding protein like, } \\
\text { helix-loop-helix }(\mathrm{bHLH}) \text { proteins }\end{array}$ & $\begin{array}{l}\text { TraesCS4B02G287900 } \\
\text { (MQTL4B.8) }\end{array}$ & $\begin{array}{l}\text { Heang et al. } \\
(2012)\end{array}$ \\
\hline 12. & ${ }^{\mathrm{a}} q G L 3(\mathrm{GS})$ & $\begin{array}{l}\text { similar to serine/threonine protein } \\
\text { phosphatase }\end{array}$ & $\begin{array}{l}\text { TraesCS5A02G030300 } \\
\text { (MQTL5A.1), } \\
\text { TraesCS5B02G029100 } \\
\text { (MQTL5B.8) }\end{array}$ & $\begin{array}{l}\text { Qi et al. } \\
(2012)\end{array}$ \\
\hline 13. & ${ }^{\mathrm{a}} S M G 1$ (GS) & $\begin{array}{l}\text { mitogen-activated protein kinase kinase } \\
4,\end{array}$ & $\begin{array}{l}\text { TraesCS6B02G379500 } \\
\text { (MQTL6B.10), } \\
\text { TraesCS6D02G328800 } \\
\text { (MQTL6D.1, MQTL6D.2, } \\
\text { MQTL6D.3) }\end{array}$ & $\begin{array}{l}\text { Duan et al. } \\
(2014)\end{array}$ \\
\hline 14. & $\begin{array}{l}\text { a OsOTUB1 (TN, } \\
\text { GN, GWei) }\end{array}$ & $\begin{array}{l}\text { squamosa promoter-binding-like protein } \\
14\end{array}$ & $\begin{array}{l}\text { TraesCS5D02G273900 } \\
\text { (MQTL5D.3, MQTL5D.5) }\end{array}$ & $\begin{array}{l}\text { Wang et al. } \\
\text { (2017) }\end{array}$ \\
\hline 15. & a $O s L G 3(\mathrm{GL})$ & $\begin{array}{l}\text { APETALA2/ethylene-responsive element } \\
\text { binding protein } 125\end{array}$ & $\begin{array}{l}\text { TraesCS6A02G097500 } \\
\text { (MQTL6A.2), } \\
\text { TraesCS6B02G375400 } \\
\text { (MQTL6B.10) }\end{array}$ & $\begin{array}{l}\text { Yu et al. } \\
(2017)\end{array}$ \\
\hline 16. & ${ }^{\mathrm{a}} \mathrm{OsDHHC1}(\mathrm{TN})$ & $\begin{array}{l}\text { Zinc finger, DHHC-type domain } \\
\text { containing protein }\end{array}$ & $\begin{array}{l}\text { TraesCS6D02G379300 } \\
\text { (MQTL6D.1) }\end{array}$ & $\begin{array}{l}\text { Zhou et al. } \\
(2017)\end{array}$ \\
\hline 17. & ${ }^{\mathrm{a}}$ OsY37(DTH) & protein similar to GRAB2 & $\begin{array}{l}\text { TraesCS7D02G452500 } \\
\text { (MQTL7D.5) }\end{array}$ & $\begin{array}{l}\text { Mannai et al. } \\
\text { (2017) }\end{array}$ \\
\hline 18. & ${ }^{\mathrm{a}} q W S 8(\mathrm{PBN})$ & SBP-domain transcription factor & $\begin{array}{l}\text { TraesCS5D02G273900 } \\
\text { (MQTL5D.3, MQTL5D.5) }\end{array}$ & $\begin{array}{l}\text { Zhang et al. } \\
\text { (2017) }\end{array}$ \\
\hline 19. & ${ }^{\mathrm{a}} O s A L M T 7(\mathrm{PD})$ & $\begin{array}{l}\text { aluminum-activated malate transporter } \\
10\end{array}$ & $\begin{array}{l}\text { TraesCS6A02G255200 } \\
\text { (MQTL6A.2), } \\
\text { TraesCS6B02G270300 } \\
\text { (MQTL6B.10) }\end{array}$ & $\begin{array}{l}\text { Heng et al. } \\
(2018)\end{array}$ \\
\hline 20. & ${ }^{\mathrm{a}} G S 9$ (GS) & uncharacterized protein & $\begin{array}{l}\text { TraesCS5A02G233400 } \\
\text { (MQTL5A.4), } \\
\text { TraesCS5D02G240300 } \\
\text { (MQTL5D.3, MQTL5D.5) }\end{array}$ & $\begin{array}{l}\text { Zhao et al. } \\
\text { (2018) }\end{array}$ \\
\hline
\end{tabular}




\begin{tabular}{|c|c|c|c|c|}
\hline 21. & 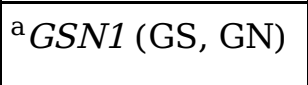 & $\begin{array}{l}\text { mitogen-activated protein kinase } \\
\text { phosphatase }\end{array}$ & $\begin{array}{l}\text { TraesCS1A02G045300 } \\
\text { (MQTL1A.2) }\end{array}$ & $\begin{array}{l}\text { Guo et al. } \\
(2018)\end{array}$ \\
\hline 22. & $\begin{array}{l}\text { a } O s P S 1-F(\mathrm{PH}, \\
\mathrm{TN})\end{array}$ & $\begin{array}{l}\text { Oryza sativa PHOTOSYSTEM 1-F } \\
\text { subunit }\end{array}$ & $\begin{array}{l}\text { TraesCS5D02G422800 } \\
\text { (MQTL5D.1, MQTL5D.3) }\end{array}$ & $\begin{array}{l}\text { Ramamoorthy } \\
\text { et al. (2018) }\end{array}$ \\
\hline 23. & $\begin{array}{l}{ }^{\mathrm{a}} \text { OsPK2 (SD, } \\
\mathrm{GF})\end{array}$ & protein similar to pyruvate kinase & $\begin{array}{l}\text { TraesCS2A02G240200 } \\
\text { (MQTL2A.2), } \\
\text { TraesCS2D02G237900 } \\
\text { (MQTL2D.8) }\end{array}$ & $\begin{array}{l}\text { Cai et al. } \\
(2018)\end{array}$ \\
\hline \multirow[t]{2}{*}{24.} & $F Z P(G S)$ & $\begin{array}{l}\text { ethylene-responsive transcription factor } \\
\text { FZP-like }\end{array}$ & $\begin{array}{l}\text { TraesCS2A02G116900 } \\
\text { (MQTL2A.1), } \\
\text { TraesCS2D02G118200 } \\
\text { (MQTL2D.5, MQTL2D.8) }\end{array}$ & $\begin{array}{l}\text { Ren et al. } \\
(2018)\end{array}$ \\
\hline & \multicolumn{4}{|l|}{ Barley } \\
\hline 25. & $H v C K X 2(\mathrm{YA})$ & cytokinin oxidase/dehydrogenase & $\begin{array}{l}\text { TraesCS1D02G237200 } \\
\text { (MQTL1D.4) }\end{array}$ & $\begin{array}{l}\text { Galuszka et } \\
\text { al. (2004) }\end{array}$ \\
\hline 26. & ${ }^{\mathrm{a}} \operatorname{Vrs} 4$ (IA) & LOB domain TF HvRA2 & $\begin{array}{l}\text { TraesCS3A02G093200 } \\
\text { (MQTL3A.3), } \\
\text { TraesCS3D02G093500 } \\
\text { (MQTL3D.6) }\end{array}$ & $\begin{array}{l}\text { Koppolu et al. } \\
\text { (2013) }\end{array}$ \\
\hline \multirow[t]{2}{*}{27.} & ${ }^{\mathrm{a}} \mathrm{COM1}(\mathrm{IA})$ & AP2/ERF transcription factor & $\begin{array}{l}\text { TraesCS5A02G207300 } \\
\text { (MQTL5A.4), } \\
\text { TraesCS5D02G213400 } \\
\text { (MQTL5.3) }\end{array}$ & $\begin{array}{l}\text { Poursarebani } \\
\text { et al. (2020) }\end{array}$ \\
\hline & \multicolumn{4}{|l|}{ Maize } \\
\hline 28. & $\begin{array}{l}{ }^{\mathrm{a}} F A S C I A T E D \\
\text { EAR2 (KRN) }\end{array}$ & leucine-rich repeat receptor-like protein & $\begin{array}{l}\text { TraesCS6A02G214600 } \\
\text { (MQTL6A.2), } \\
\text { TraesCS6B02G244700 } \\
\text { (MQTL6B.10) }\end{array}$ & $\begin{array}{l}\text { Bommert et } \\
\text { al. (2013) }\end{array}$ \\
\hline 29. & a ramosa2 (IA) & LOB Domain Protein & $\begin{array}{l}\text { TraesCS3A02G093200 } \\
\text { (MQTL3A.3), } \\
\text { TraesCS3D02G093500 } \\
\text { (MQTL3D.6) }\end{array}$ & $\begin{array}{l}\text { Bortiri et al. } \\
(2006)\end{array}$ \\
\hline 30. & a ZmFrk1 (GD) & fructokinase & $\begin{array}{l}\text { TraesCS5D02G293800 } \\
\text { (MQTL5D.3) }\end{array}$ & $\begin{array}{l}\text { Zhang et al. } \\
(2003)\end{array}$ \\
\hline 31. & ${ }^{a} b s 1$ (IA) & a putative ERF transcription factor & $\begin{array}{l}\text { TraesCS2A02G116900 } \\
\text { (MQTL2A.1), } \\
\text { TraesCS2D02G118200 } \\
\text { (MQTL2D.8) }\end{array}$ & $\begin{array}{l}\text { Chuck et al. } \\
(2002)\end{array}$ \\
\hline 32. & ${ }^{\mathrm{a}} B I F 1$ (IA) & $\begin{array}{l}\text { AUXIN/INDOLE-3-ACETIC ACID } \\
\text { (Aux/IAA) protein }\end{array}$ & $\begin{array}{l}\text { TraesCS5A02G058600 } \\
\text { (MQTL5A.3) }\end{array}$ & $\begin{array}{l}\text { Galli et al. } \\
\text { (2015) }\end{array}$ \\
\hline 33. & $Z m G S 3$ (SD) & protein with 198 amino acids & $\begin{array}{l}\text { TraesCS7A02G017700 } \\
\text { (MQTL7A.1), } \\
\text { TraesCS6B02G136400 } \\
\text { (MQTL6B.10) }\end{array}$ & $\begin{array}{l}\text { Li et al. } \\
(2010)\end{array}$ \\
\hline 34. & $Z m V T 2(\mathrm{IA})$ & $\begin{array}{l}\text { grass-specific tryptophan } \\
\text { aminotransferase }\end{array}$ & $\begin{array}{l}\text { TraesCS3A02G093000 } \\
\text { (MQTL3A.3) }\end{array}$ & $\begin{array}{l}\text { Phillips et al. } \\
\text { (2011) }\end{array}$ \\
\hline 35. & ${ }^{\mathrm{a}} K N R 6(\mathrm{KRN})$ & a serine/threonine protein kinase & $\begin{array}{l}\text { TraesCS7D02G451300 } \\
\text { (MQTL7D.5) }\end{array}$ & $\begin{array}{l}\text { Jia et al. } \\
(2020)\end{array}$ \\
\hline
\end{tabular}

GN grain number, GS grain size, PH plant height, FD floral development, GY grain yield, GL grain length, PA panicle architecture, PE panicle erectness, GF grain filling, GWei Grain weight, GW grain width, PB panicle branching, PL panicle length, TN tiller number, DTH days to heading, PBN primary branch number, PD panicle development, SD seed development, YA yield attributes, IA inflorescence architecture, and KRN kernel row number

${ }^{\mathrm{a}}$ Orthologs of these genes have not yet been functionally characterized in wheat.

Table 5 Putative candidate genes (only those genes which had >5 TPM expression) of MQTLs 


\begin{tabular}{|c|c|}
\hline \multirow{3}{*}{$\begin{array}{l}\text { MQTL name } \\
\text { MQTL1A.2 }\end{array}$} & Putative Gene ID \\
\hline & TraesCS1A02G043600 \\
\hline & TraesCS1A02G044200 \\
\hline \multirow{2}{*}{ MQTL1A.3 } & TraesCS1A02G040600 \\
\hline & TraesCS1A02G041300 \\
\hline MQTL1A.4 & TraesCS1A02G042700 \\
\hline MQTL1A.6 & TraesCS1A02G060700 \\
\hline \multirow[t]{2}{*}{ MQTL1A.7 } & TraesCS1A02G046500 \\
\hline & TraesCS1A02G047000 \\
\hline \multirow{2}{*}{ MQTL1A.8 } & TraesCS1A02G050400 \\
\hline & TraesCS1A02G050800 \\
\hline \multirow[t]{2}{*}{ MQTL1B.1 } & TraesCS1B02G006500 \\
\hline & TraesCS1B02G008000 \\
\hline MQTL1B.2 & TraesCS1B02G068200 \\
\hline MQTL1B.3 & TraesCS1B02G020700 \\
\hline MQTL1B.5 & TraesCS1B02G036500 \\
\hline MQTL1B.4 & TraesCS1B02G026500 \\
\hline \multirow[t]{2}{*}{ MQTL1B.7 } & TraesCS1B02G223600 \\
\hline & TraesCS1B02G224300 \\
\hline \multirow{2}{*}{ MQTL1B.8 } & TraesCS1B02G261700 \\
\hline & TraesCS1B02G262000 \\
\hline MQTL1D.1 & TraesCS1D02G003900 \\
\hline MQTL1D.6 & TraesCS1D02G037900 \\
\hline \multirow{3}{*}{$\begin{array}{l}\text { MQTL2A.2 } \\
\text { MQTL2A.3 }\end{array}$} & TraesCS2A02G245900 \\
\hline & TraesCS2A02G089300 \\
\hline & TraesCS2A02G090000 \\
\hline MQTL2A.4 & TraesCS2A02G064300 \\
\hline \multirow[t]{2}{*}{ MQTL2A.5 } & TraesCS2A02G065100 \\
\hline & TraesCS2A02G065700 \\
\hline MQTL2A.6 & TraesCS2A02G071500 \\
\hline MQTL2A.7 & TraesCS2A02G086400 \\
\hline \multirow{2}{*}{ MQTL2B.1 } & TraesCS2B02G027000 \\
\hline & TraesCS2B02G030700 \\
\hline MQTL2B.2 & TraesCS2B02G053200 \\
\hline MQTL2B.3 & TraesCS2B02G059500 \\
\hline \multirow{3}{*}{$\begin{array}{l}\text { MQTL2B.4 } \\
\text { MQTL2B.6 }\end{array}$} & TraesCS2B02G063500 \\
\hline & TraesCS2B02G020400 \\
\hline & TraesCS2B02G021500 \\
\hline MOTL2B 7 & TraesCS2B02G090300 \\
\hline MQTL2D.1 & TraesCS2D02G006500 \\
\hline \multirow{3}{*}{ MQTL2D.2 } & TraesCS2D02G020900 \\
\hline & TraesCS2D02G021500 \\
\hline & TraesCS2D02G022700 \\
\hline \multirow[t]{2}{*}{ MQTL2D.3 } & TraesCS2D02G057000 \\
\hline & TraesCS2D02G055000 \\
\hline MQTL2D.5 & TraesCS2D02G099400 \\
\hline & TraesCS2D02G100300 \\
\hline MQTL2D.6 & TraesCS2D02G047800 \\
\hline & TraesCS2D02G049500 \\
\hline MQTL2D.8 & TraesCS2D02G250300 \\
\hline & TraesCS2D02G251000 \\
\hline MQTL3A.1 & TraesCS3A02G008700 \\
\hline & TraesCS3A02G011100 \\
\hline MQTL3A.2 & TraesCS3A02G003800 \\
\hline MQTL3A.3 & TraesCS3A02G097100 \\
\hline & TraesCS3A02G099200 \\
\hline MQTL3A.4 & TraesCS3A02G041800 \\
\hline MQTL3A.5 & TraesCS3A02G049600 \\
\hline MQTL3A.6 & TraesCS3A02G044800 \\
\hline MQTL3A.7 & TraesCS3A02G033900 \\
\hline MQTL3A.8 & TraesCS3A02G490300 \\
\hline & TraesCS3A02G489700 \\
\hline MQTL3B.1 & TraesCS3B02G045700 \\
\hline & TraesCS3B02G047300 \\
\hline MQTL3B.2 & TraesCS3B02G050500 \\
\hline & TraesCS3B02G052600 \\
\hline MQTL3B.4 & TraesCS3B02G061700 \\
\hline MQTL3B.6 & TraesCS3B02G048900 \\
\hline
\end{tabular}

Gene Function Description

RNA polymerase II transcription factor SIII

WD40/YVTN repeat-like-containing protein

Phosphoglucose isomerase

Proteinase inhibitor I13

SANT/Myb protein

Ribosomal biogenesis regulatory protein

E3 UFM1-protein ligase 1

HAD-like superfamily

SWEET sugar transporter

Defensin

Serine/threonine-protein kinase

RNA-binding domain superfamily

HSP20-like chaperone

Serine/threonine-protein kinase

Calcium-dependent channel

Leucine-rich repeat protein

Putative NADH dehydrogenase

Trehalose-phosphatase

GDSL lipase/esterase

Oxoglutarate/iron-dependent dioxygenase

Ribosomal protein L28/L24

Chalcone isomerase

Ribosomal protein S19

Heat shock transcription factor family

P-loop containing nucleoside triphosphate hydrolase Zinc finger protein

Protein-tyrosine phosphatase

Major intrinsic protein

Flavin monooxygenase

P-loop containing nucleoside triphosphate hydrolase

Protein kinase-like domain superfamily

Zinc finger protein

Glycoside hydrolase

Flowering-promoting factor 1

P-loop containing nucleoside triphosphate hydrolase

Polycomb protein

Protein kinase-like domain superfamily

RmlC-like cupin protein

Cytochrome P450 protein

Photosystem II PsbI

Cytochrome $\mathrm{P} 450$ protein

Chalcone/stilbene synthase

Glycoside hydrolase

UDP-glycosyltransferase

Ethylene insensitive 3-like protein

Zinc finger protein

Defensin

Chaperonin containing TCP-1

P-loop containing nucleoside triphosphate hydrolase

RNA-binding protein

Aquaporin transporter

Expansin

Thiolase-like

Sugar phosphate transporter

AP2/ERF

Tryptophan synthase

Serine/threonine-protein kinase

Mannose-6-phosphate isomerase

HSP20-like chaperone

Flavoprotein-like protein

Helix-loop-helix DNA-binding protein

Glycoside hydrolase family 10

Sugar/inositol transporter

Mitochondrial carriers

Serine/threonine-protein kinase

Photosystem I PsaL

Short-chain dehydrogenase/reductase 


\begin{tabular}{|c|c|c|}
\hline MQTL3B.7 & TraesCS3B02G517100 & RNA-binding protein \\
\hline MQTL3D.1 & TraesCS3D02G037600 & Ribosomal protein S10 \\
\hline \multirow[t]{2}{*}{ MQTL3D.2 } & TraesCS3D02G024500 & Glycosyltransferase 61 \\
\hline & TraesCS3D02G024700 & Cytochrome P450 protein \\
\hline MQTL3D.3 & TraesCS3D02G046700 & HSP20-like chaperone \\
\hline MQTL3D.4, \& 5 & TraesCS3D02G063100 & Serine/threonine-protein kinase \\
\hline MQTL3D.6 & TraesCS3D02G099900 & Golgi to ER traffic protein 4 \\
\hline MQTL3D.7 & TraesCS3D02G126500 & UDP-glucuronosyl/UDP-glucosyltransferase \\
\hline MQTL3D.9 & TraesCS3D02G446700 & C2 domain superfamily \\
\hline \multirow[t]{2}{*}{ MQTL4A.1 } & TraesCS4A02G00740 & Thiolase-like \\
\hline & TraesCS4A02G011300 & Protein of unknown function DUF538 \\
\hline MQTL4A.2 & TraesCS4A02G035400 & AP2/ERF \\
\hline MQTL4A.3, 4 \& 5 & TraesCS4A02G442900 & Peroxisomal biogenesis factor 11 \\
\hline MQTL4B.1 & TraesCS4B02G005900 & Cytochrome P450 protein \\
\hline MQTL4B.2 & TraesCS4B02G011500 & HPT domain superfamily \\
\hline MQTL4B.3 & TraesCS4B02G015100 & Replication factor A protein-like \\
\hline MQTL4B.4 & TraesCS4B02G017500 & RmlC-like cupin \\
\hline MQTL4B.5 & TraesCS4B02G020300 & RNA-binding protein \\
\hline \multirow[t]{2}{*}{ MQ'TL4B.7 } & TraesCS4B02G321200 & Fasciclin-like arabinogalactan protein \\
\hline & TraesCS4B02G321300 & Glycosyl transferase \\
\hline MQTL4B.8 & TraesCS4B02G266700 & GRAS TF \\
\hline \multirow[t]{2}{*}{ MQTL4D.1 } & TraesCS4D02G014100 & WRKY TF \\
\hline & TraesCS4D02G018100 & Zinc finger protein \\
\hline MQTL4D.2 & TraesCS4D02G012100 & Short-chain dehydrogenase/reductase \\
\hline MQTL4D.3 & TraesCS4D02G008700 & Signal transduction histidine kinase \\
\hline \multirow{2}{*}{ MQTL4D.4 } & TraesCS4D02G006100 & Glycoside hydrolase \\
\hline & TraesCS4D02G006900 & Ubiquitin-like protein \\
\hline MQTL4D.5 & TraesCS4D02G003100 & Major facilitator superfamily \\
\hline \multirow[t]{2}{*}{ MQTL4D.8 } & TraesCS4D02G021100 & MADS-box TF \\
\hline & TraesCS4D02G022600 & Homeobox-like domain superfamily \\
\hline \multirow[t]{3}{*}{ MQTL4D.10 } & TraesCS4D02G064400 & WD40/YVTN repeat-like-containing protein \\
\hline & TraesCS4D02G065300 & MFS transporter superfamily \\
\hline & TraesCS4D02G065600 & Glycoside hydrolase family 9 \\
\hline MQTL5A.1 & TraesCS5A02G025900 & YABBY protein \\
\hline MQTL5A.2 & TraesCS5A02G019200 & Fatty acid hydroxylase \\
\hline MQTL5A.3 & TraesCS5A02G110200 & Pentatricopeptide repeat \\
\hline \multirow{2}{*}{ MQTL5A.4 } & TraesCS5A02G196400 & Ubiquitin-like domain superfamily \\
\hline & TraesCS5A02G197000 & Protein kinase-like domain superfamily \\
\hline MQTL5B.1 & TraesCS5B02G080200 & Ubiquitin-like domain superfamily \\
\hline \multirow[t]{2}{*}{ MQTL5B.3 } & TraesCS5B02G007100 & Cytochrome P450 protein \\
\hline & TraesCS5B02G007500 & Ankyrin repeat-containing protein \\
\hline \multirow[t]{2}{*}{ MQTL5B.4 } & TraesCS5B02G010500 & Thiolase-like \\
\hline & TraesCS5B02G011700 & Glycoside hydrolase \\
\hline \multirow[t]{2}{*}{ MQTL5B.5 \& 6} & TraesCS5B02G013200 & RNA recognition motif domain \\
\hline & TraesCS5B02G014400 & Small GTPase \\
\hline MQTL5B.7 & TraesCS5B02G015000 & ATP synthase \\
\hline \multirow[t]{2}{*}{ MQTL5B.8 } & TraesCS5B02G028300 & Short-chain dehydrogenase/reductase \\
\hline & TraesCS5B02G029000 & Regulator of K+ conductance \\
\hline \multirow[t]{2}{*}{ MQTL5D.1 } & TraesCS5D02G431400 & Armadillo-like helical \\
\hline & TraesCS5D02G430000 & Clathrin adaptor complex \\
\hline MQTL5D.2 & TraesCS5D02G044100 & Subtilisin-like protease \\
\hline \multirow[t]{3}{*}{ MQTL5D.4 } & TraesCS5D02G536500 & Nucleotide-diphospho-sugar transferase \\
\hline & TraesCS5D02G536100 & Mitochondrial carrier \\
\hline & TraesCS5D02G535400 & Cytochrome P450 protein \\
\hline MQTL5D.5 & TraesCS5D02G211200 & TIFY/JAZ family \\
\hline & TraesCS5D02G211900 & Ubiquitin-like domain superfamily \\
\hline MQTL6A.1 & TraesCS6A02G325400 & Oxoglutarate/iron-dependent dioxygenase \\
\hline & TraesCS6A02G325100 & Transcription elongation factor Spt5 \\
\hline & TraesCS6A02G325300 & Glycoside hydrolase \\
\hline MQTL6A.2 & TraesCS6A02G196800 & RmlC-like jelly roll fold \\
\hline MQTL6A.3 & TraesCS6A02G196600 & Glycosyltransferase \\
\hline MQTL6B.1 & TraesCS6B02G313100 & WD40/YVTN repeat-like-containing protein \\
\hline & TraesCS6B02G313400 & GPI-anchored protein LORELEI-like \\
\hline MQTL6B.2 \& 3 & TraesCS6B02G012100 & GroEL-like apical domain superfamily \\
\hline MQTL6B.7 & TraesCS6B02G017700 & RNA-binding protein \\
\hline MQTL6B.10 & TraesCS6B02G224800 & Translation elongation factor EFTu-like \\
\hline MQTL6D.1 & TraesCS6D02G392100 & Glycoside hydrolase \\
\hline
\end{tabular}




\begin{tabular}{|c|c|c|}
\hline & TraesCS6D02G392600 & Serine/threonine-protein kinase \\
\hline \multirow[t]{2}{*}{ MQTL6D.2 } & TraesCS6D02G331400 & Amino acid transporter \\
\hline & TraesCS6D02G330800 & Diacylglycerol kinase \\
\hline \multirow[t]{2}{*}{ MQTL6D.3 } & TraesCS6D02G334000 & Glycosyl transferase \\
\hline & TraesCS6D02G332900 & Dehydrin \\
\hline MQTL6D.4 & TraesCS6D02G375700 & Serine/threonine-protein kinase \\
\hline \multirow[t]{2}{*}{ MQTL6D.5 } & TraesCS6D02G399500 & Leucine-rich repeat protein \\
\hline & TraesCS6D02G397800 & Gibberellin regulated protein \\
\hline \multirow[t]{2}{*}{ MQTL7A.1 } & TraesCS7A02G014100 & Ribosomal protein L9 \\
\hline & TraesCS7A02G015300 & Serine-threonine/tyrosine-protein kinase \\
\hline \multirow[t]{2}{*}{ MQTL7A.2 } & TraesCS7A02G009400 & Glycoside hydrolase \\
\hline & TraesCS7A02G009900 & WD40/YVTN repeat-like-containing protein \\
\hline MQTL7A.3 & TraesCS7A02G082000 & Ribosomal protein L5 \\
\hline \multirow[t]{2}{*}{ MQTL7B.1 } & TraesCS7B02G008400 & F-box-like domain superfamily \\
\hline & TraesCS7B02G009200 & Mitogen-activated protein kinase \\
\hline MQTL7B.2 & TraesCS7B02G031400 & Casparian strip membrane protein \\
\hline MQTL7B.5 & TraesCS7B02G304500 & Glycoside hydrolase \\
\hline \multirow{2}{*}{ MQTL7B.6 } & TraesCS7B02G450100 & Senescence/spartin-associated \\
\hline & TraesCS7B02G451200 & SWEET sugar transporter \\
\hline \multirow[t]{2}{*}{ MQTL7D.1 } & TraesCS7D02G036600 & Sucrose synthase \\
\hline & TraesCS7D02G036900 & Cytochrome P450 protein \\
\hline \multirow[t]{2}{*}{ MQTL7D.2 } & TraesCS7D02G106400 & Mitogen-activated protein kinase \\
\hline & TraesCS7D02G108900 & GDSL lipase/esterase \\
\hline MQTL7D.3 & TraesCS7D02G398900 & Glycoside hydrolase \\
\hline \multirow[t]{4}{*}{ MQTL7D.5 } & TraesCS7D02G455900 & Small auxin-up RNA \\
\hline & TraesCS7D02G456600 & Ribosomal protein S13 \\
\hline & TraesCS7D02G457400 & SANT/Myb protein \\
\hline & TraesCS7D02G458200 & Papain-like cysteine peptidase \\
\hline
\end{tabular}

\section{Figures}




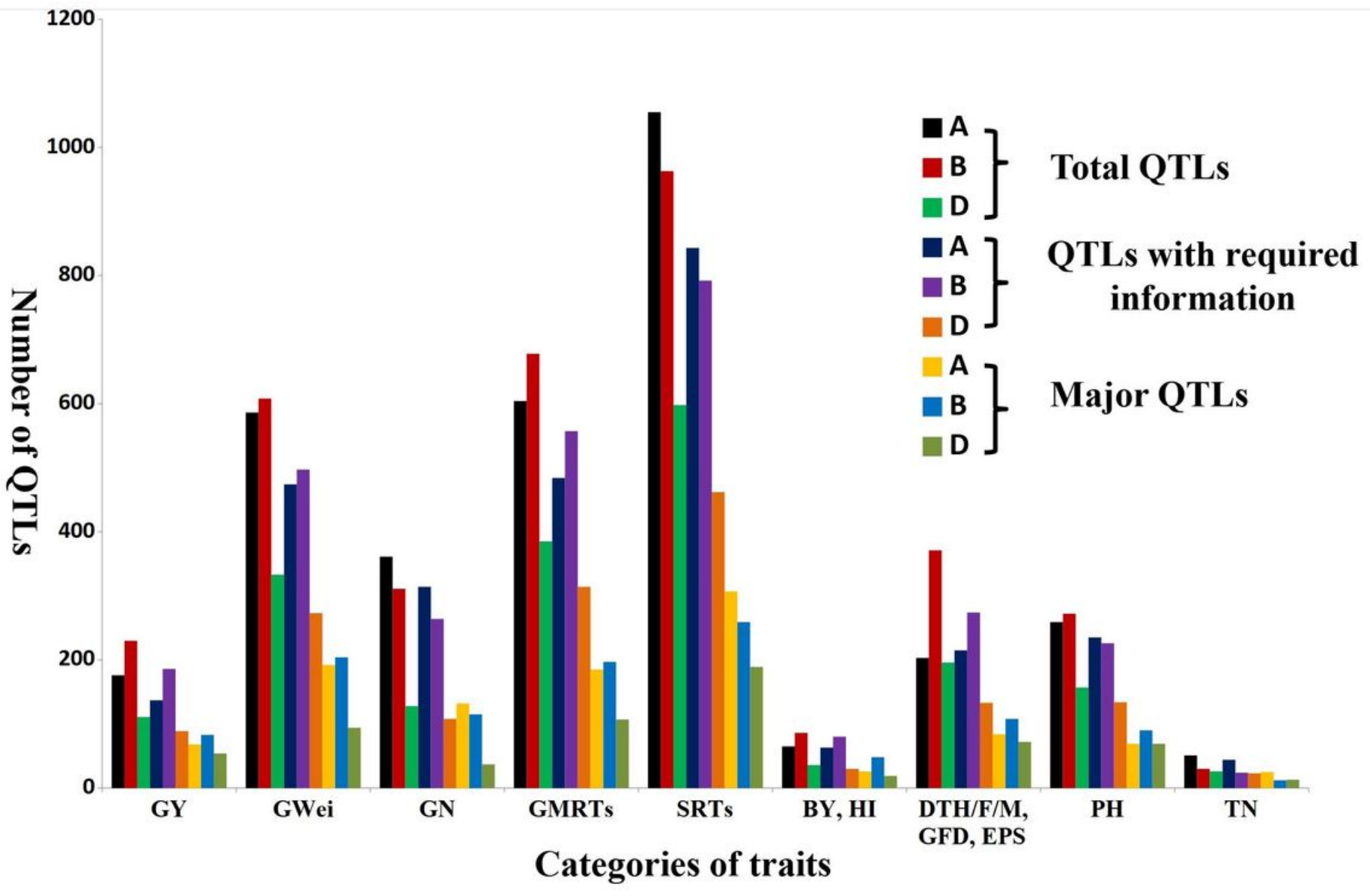

Figure 1

Distribution of collected QTLs for grain yield and associated traits on A, B and D sub-genomes of wheat. 


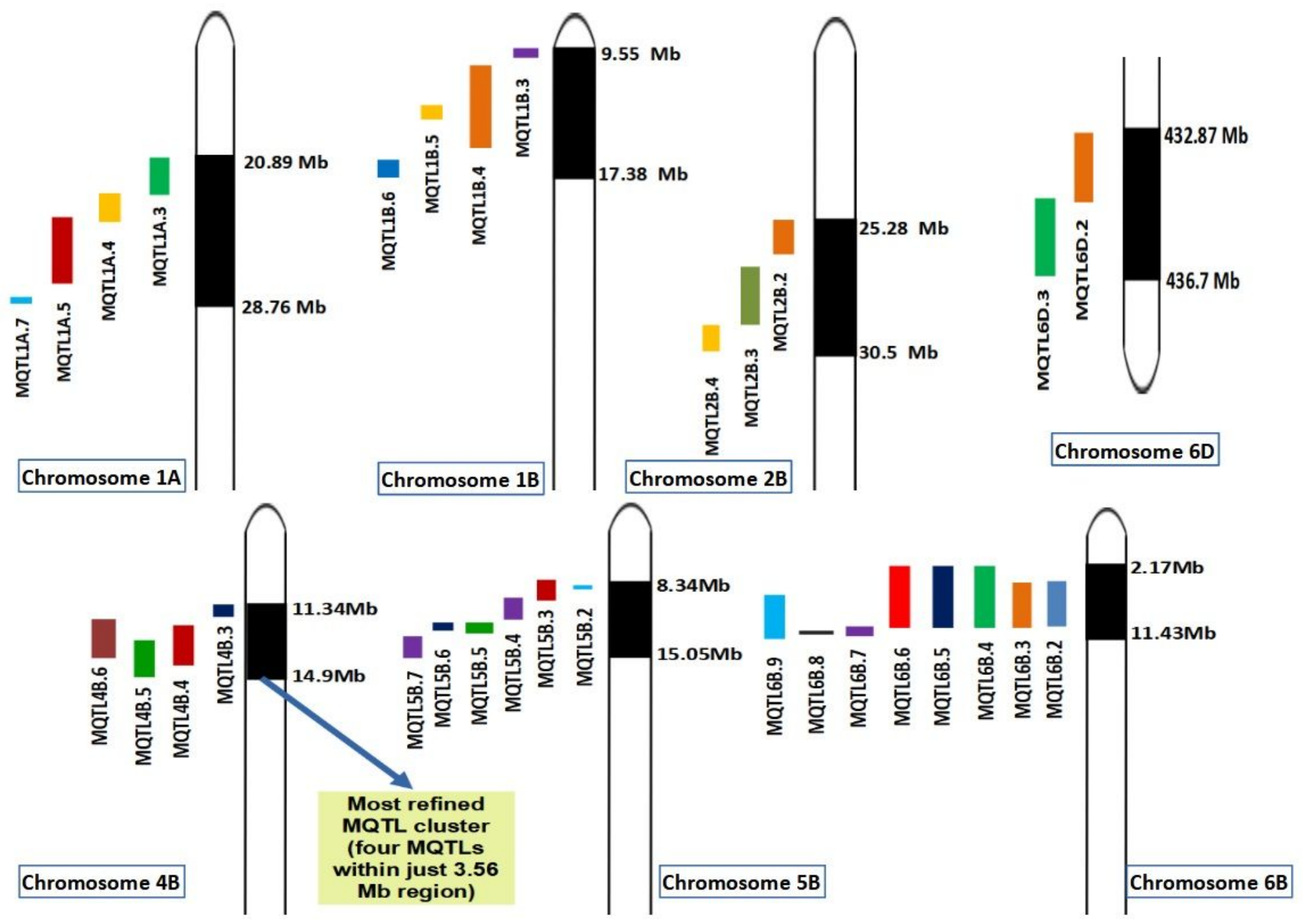

Figure 2

Diagrammatic representation of MQTL clusters detected on chromosomes 1A, 1B, 2B, 4B, 5B, 6B and 6D; Only desired parts of the chromosomes are shown for better visualization; different colours correspond to different MQTLs on each chromosome. 


1101010010101001001001
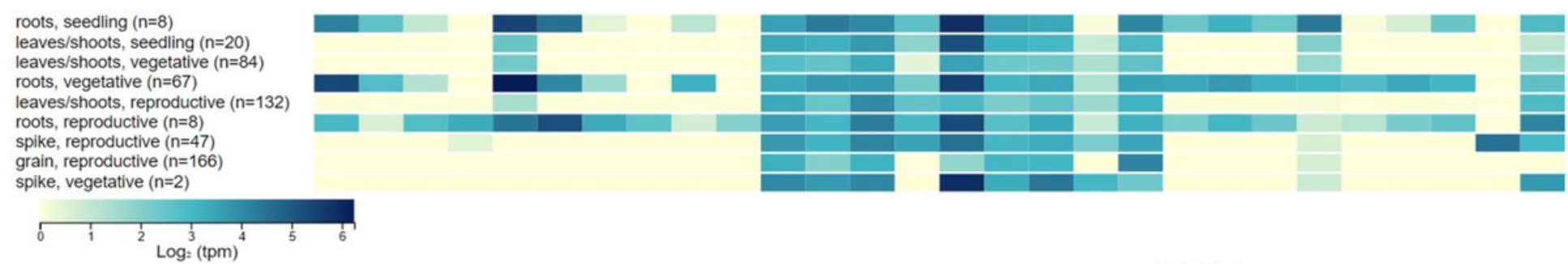

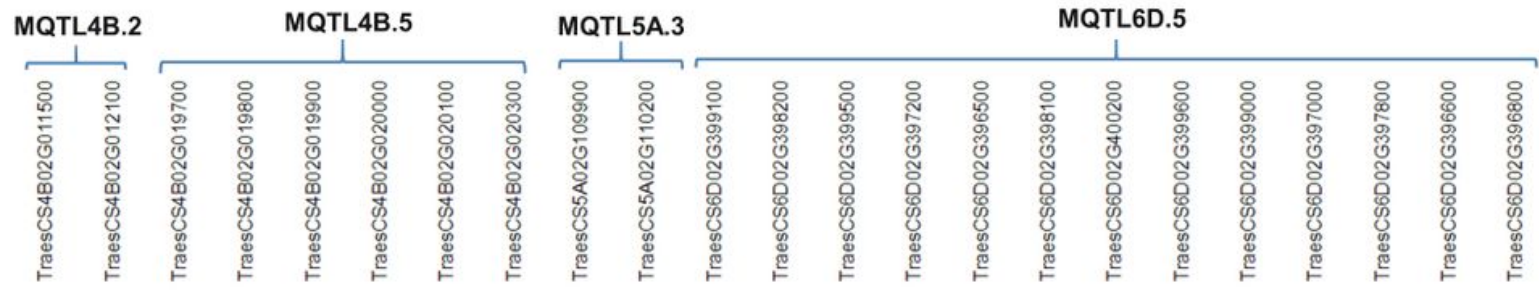

roots, seedling $(n=8)$

leaves/shoots, seedling $(n=20)$

leaves/shoots, vegetative $(n=84)$

roots, vegetative $(n=67)$

leaves/shoots, reproductive $(n=132)$

roots, reproductive $(n=8)$

spike, reproductive $(n=47$

grain, reproductive $(n=166)$

spike, vegetative $(n=2)$
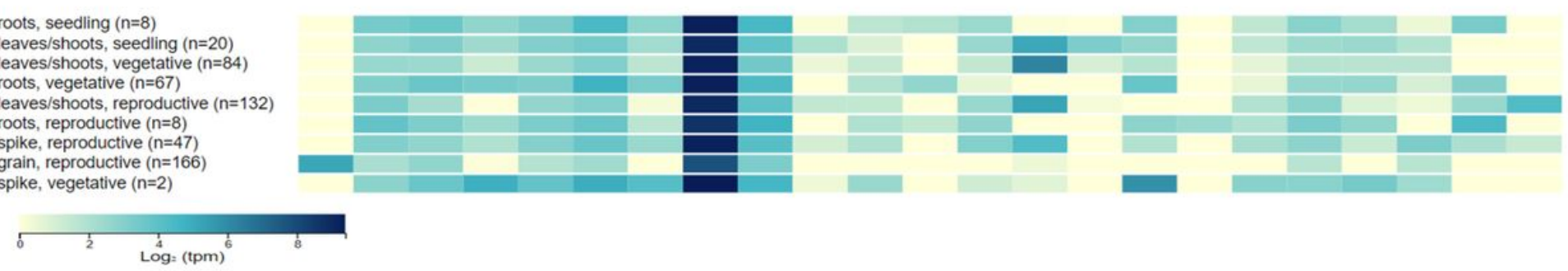

Figure 3

Heatmaps showing differential expression of important candidate genes underlying some selected Breeder's MQTLs. The scale drawn on the lower left of each heatmap represents the range of TPM values.

\section{Supplementary Files}

This is a list of supplementary files associated with this preprint. Click to download.

- Supplementarymaterial1.xls 